\title{
Recent Advances in Acoustic Metamaterials for Simultaneous Sound Attenuation and Air Ventilation Performances
}

\author{
Sanjay Kumar *(1) and Heow Pueh Lee \\ Department of Mechanical Engineering, National University of Singapore, 9 Engineering Drive 1, \\ Singapore 117575, Singapore; mpeleehp@nus.edu.sg \\ * Correspondence: mpesanj@nus.edu.sg
}

Received: 13 July 2020; Accepted: 5 August 2020; Published: 7 August 2020

check for updates

\begin{abstract}
In the past two decades, acoustic metamaterials have garnered much attention owing to their unique functional characteristics, which are difficult to find in naturally available materials. The acoustic metamaterials have demonstrated excellent acoustical characteristics that paved a new pathway for researchers to develop effective solutions for a wide variety of multifunctional applications, such as low-frequency sound attenuation, sound wave manipulation, energy harvesting, acoustic focusing, acoustic cloaking, biomedical acoustics, and topological acoustics. This review provides an update on the acoustic metamaterials' recent progress for simultaneous sound attenuation and air ventilation performances. Several variants of acoustic metamaterials, such as locally resonant structures, space-coiling, holey and labyrinthine metamaterials, and Fano resonant materials, are discussed briefly. Finally, the current challenges and future outlook in this emerging field are discussed as well.
\end{abstract}

Keywords: acoustic metamaterials; sound attenuation; air ventilation; architectural acoustics

\section{Acoustic Metamaterials: A Brief Overview}

The concept of metamaterial research initially originates from electromagnetics, which is based upon the fundamental Maxwell's equations. Prof. Veselago proposed the first primary hypothesis related to metamaterials in 1968 that discussed the possibility of materials with simultaneously negative fundamental parameters, namely permittivity $\varepsilon$, and permeability $\mu$ for manipulating electromagnetic waves [1]. However, the term 'metamaterial' was first coined by R. M. Walser [2]. He defined metamaterials as "macroscopic composites having a manmade, three-dimensional, periodic cellular architecture designed to produce an optimized combination, not available in nature, of two or more responses to specific excitation".

The metamaterial research revolution started when Pendry et al. [3] theoretically demonstrated a decrease of the plasma frequency in a regular array of a thin metallic wire microstructure in the $\mathrm{GHz}$ band. In 1999, for the first time, the concept was experimentally investigated in which negative permeability was realized from the copper etched 'split-ring' type resonators [4]. In 2001, Shelby et al. [5] experimentally demonstrated the wave propagation in negative-index media. The structure was constructed by stacking multiple copper split-ring resonators and wire strips into a periodic array on fiberglass circuit board material. They termed their fabricated structure as the 'left-handed' metamaterial. This finding was a milestone in the field of metamaterials. Following these research works, the field of metamaterials has been expanded in many areas like electromagnetics [6,7], optics [8-10], and acoustics [11-15].

The optics counterpart was termed as photonic crystals, while the acoustic counterpart was termed as phononic crystals. The photonic crystals possess effective medium characteristics like 
negative permittivity and permeability, and thus have an effectively negative refractive index. The photonic crystals were first proposed in 1987 [16-18] for propagating the optical wave in refraction index-modulated periodic structures analogous to the propagation of electrons in real crystals. Since then, the photonic crystals have shown some outstanding phenomena, such as left-handed backward effects, negative refractions [19], inverse Doppler effects [20,21], inverse Cherenkov effects [22,23], and superlens [24].

In parallel with photonic crystals' evolutions, the phononic crystals were conceived with elastic waves propagating in periodic structures modulated with periodic elastic moduli and mass densities $[25,26]$. Phononic crystals are artificially engineered composite structures comprised of periodically distributed 'atoms' (single acoustic functional scatter) or inclusions in a matrix form. The high impedance contrast of elastic moduli and/or mass density of the scatterers and that of the host matrix can give rise to new acoustic dispersions and band structures due to the periodic Bragg scattering and localized Mie scatterings from the atoms or scatterers [27]. The propagation of acoustic waves in a phononic crystal is governed by the Bloch or Floquet theorem [28-30]. When a wave passes through a periodic lattice structure, constructive interference leads to band gaps that prevent wave propagation through the structure at specified frequencies. In this condition, all the energy of the incoming wave gets reflected in the source. Moreover, in case of destructive interference, all incoming wave energy is transmitted through the crystal, leading to the formation of propagation bands (passbands). The band gap formation occurs when the path differences between the interfering waves are equal to an integer multiple of the corresponding wavelength. The path difference is determined by the lattice parameter of the phononic crystal $a$, so for the occurrence of constructive interference the lattice parameter should be comparable to the wavelength of incoming waves [31]. It is possible to create a band gap of target frequency or wavelength by carefully tuning the unit cell size. Besides, the width of the band gap is directly related to the ratio of the mass densities and sound velocities in the different layers of the crystal. The width of the band gap increases with the increase of mass density contrast between the material of the scatterers and that of a host matrix [32]. Hence, in total, the elastic properties (mass density and elastic modulus), shape, location, and topology of the scatterers are the essential parameters for controlling the propagation of the acoustic/elastic waves in the structure [33].

Phononic crystals can be broadly classified into acoustic phononic crystals (APCs) with a fluid matrix and elastic phononic crystals (EPCs) with a solid elastic matrix. Initially, the phononic band structures for two-dimensional lattices of solid cylinders in the solid background were theoretically calculated by Sigalas et al. [34] and Kushwaha et al. [25] in their separate research works. The first experimental realization of the full band gap through the phononic crystals was demonstrated by Espinosa et al. [35] by using a square lattice of cylindrical holes drilled in an aluminum alloy plate, and Sánchez-Pérez et al. [36] by using a two-dimensional array of rigid cylinders. Since then, phononic crystals have shown several remarkable properties, such as band gaps, band-edge states, and the slowing of sound speed.

Inspired by these concepts, Liu et al. [11] first demonstrated an artificial acoustic metamaterial for attenuation of the sound wave. The proposed metamaterial was composed of a matrix of silicone-coated metallic spheres embedded in epoxy (see Figure 1a). The sample has shown low-frequency resonances characterized by the relative motions of the metallic sphere and silicone rubber layer. Following this pioneering work, in the past two decades, various acoustic metamaterials have been presented that offered unprecedented abilities for sound wave manipulation. Acoustic metamaterials are artificially engineered composite structures designed for unprecedented acoustic wave manipulations [37]. Two distinct effective parameters, namely, the effective mass density $\rho$ and negative bulk modulus $E$, are associated with the acoustic metamaterials and analogously with electromagnetism. These physical properties are not primarily dependent on the material constituents' intrinsic properties, but rather on the internal and geometrical structures of metamaterials. Also, these negative effective acoustic properties are dynamic and dispersive. For a homogeneous medium and plane wave, the wave propagation vector can be defined as $k=|n| \frac{\omega}{c}$, where $n=\sqrt{\rho / E}$ is the refractive index of the medium, 
$\omega$ is the angular frequency, and $c$ is the sound speed. If any of the effective parameters are negative (either $\rho<0$ or $E<0$ ), then the refractive index/phase velocity term becomes imaginary, thus the sound will not propagate through the medium. The sound wave propagation will occur only when $\rho$ and $E$ are both either simultaneously negative or positive in a specific frequency band. Negative mass density implies that acceleration is out of phase (accelerates in a direction opposite to the external sound pressure) with the dynamic pressure gradient, while a negative bulk modulus implies that volume change is out of phase (expansion of the medium upon compressive load) with the applied dynamic pressure. These negative effective properties manifest when the metamaterial's resonances are strong enough so that the scattered field prevails over the background incident field. It has been shown that a monopolar resonance could result in a negative effective bulk modulus, and a dipolar resonance could result in a negative effective mass density at certain frequencies around respective resonant frequencies [38]. These anomalous behaviors are realized through the locally resonant constituent subwavelength unit cells of the metamaterials. This kind of structure is known as a locally resonant metamaterial. The locally resonant acoustic metamaterials exhibit either one of them or both basic characteristics. Several theoretical formulations have been reported for the demonstration of negative mass density (spring-mass analogy) [39] and negative bulk modulus (Helmholtz resonance) [13,37,40].

For the realization of negative effective mass density, generally thin membranes with or without embedded mass have been used [41-43]. A thin membrane, generally made of soft materials such as natural rubber, latex, or myler sheet, is suitable for responding against incoming acoustic pressure waves. Figure 1a shows the examples of two types of acoustic metamaterials (sonic crystals [11] and decorated membrane-type metasurface [44]) designed for achieving the negative effective mass density. For the realization of negative effective bulk modulus, a Helmholtz resonator has been employed. The resonance-induced effective bulk modulus was first demonstrated by Fang et al. [45] using a waveguide consisting of an array of subwavelength Helmholtz resonators with designed acoustic inductance and capacitance. Figure $1 \mathrm{~b}$ shows the schematic description of the Helmholtz resonator, the waveguide shunted by daisy-chained Helmholtz resonators, and the effective bulk modulus spectra.

Moreover, the effective mass density and bulk modulus behaviors are associated with two distinct spatial symmetries of the particular resonances, and by overlapping the frequency-dependent response of these two symmetries, it is possible to realize double negativity. The design of these metamaterials usually involves the hybridization of two different kinds of subwavelength resonators [46-49]. The first successful experimental validation of double negativity was accomplished by Lee et al. [50] in 2010. The proposed acoustic composite structure consisted of a long hollow tube with multiple side holes separated by interspaced membranes fixed to the tube circumference (Figure 1c). The frequency dispersion in the effective mass density was induced by the thin elastic membranes, while the shunted side holes induced the frequency dispersion in the effective bulk modulus. Using their design, they achieved double negativity with a wide band gap for frequencies lower than $450 \mathrm{~Hz}$. Following this work, several strategies have been employed to achieve double negativity in several frequency ranges. Some examples for double negative acoustic metamaterials are: coupled membrane resonators [51], rubber-coated water cylinders embedded in a foam host [52], a hollow steel tube meta-atom [53], Mie resonances of porous silicone rubber spheres [54], and ultraslow fluid-like unit cells with Mie resonance [55]. Apart from the single and double negativity types, a new type of metamaterial has been presented, called near-zero acoustic metamaterial. Sound propagates with an extremely large phase velocity in these kinds of media, leading to a quasi-static spatial distribution for time-harmonic fields [56-58].

Although these resonant acoustic metamaterials have enabled advanced sound control, the resonant behaviors occur in a narrowband frequency range that substantially limits their application possibilities for meta-structures. In recent times, several designs have shown progress towards the broadening of the bandwidth. The concept of acoustic metamaterials is not limited only to locally resonant materials or periodic structures. Several other types of acoustic metamaterials have been reported, such as coiling-up space type AMs $[59,60]$, split-ring type AMs, topological 
acoustics [61], fractal acoustic metamaterials [62-66], helical-structured metamaterials [67,68], and acoustic metasurfaces [69,70]. For coiling-up space type acoustic metamaterials, the incident acoustic waves are confined in coiled subwavelength cross-section channels, thereby resulting in extraordinary acoustic properties such as double negativity and near-zero index to a high effective refractive index of unit cells [71,72]. Acoustic waves in fluids are longitudinal scalar waves. Hence, unlike electromagnetic waves, acoustic waveguides have no cut off frequency and can be confined through the narrow channels at will. By coiling the acoustic waves, the sound propagation phase is delayed such that band folding with negative dispersion $(\rho<0$ and $\mathrm{K}<0)$ is compressed towards the long-wavelength regime. Each curled unit cell purposely leads to the propagation of the airflow in confined channels, resulting in the phase delay along the elongated path and, consequently, a higher refractive index is realized. The phase delay is calculated as $\Delta \varnothing=k_{0} L_{e f f}$, where $k_{e f f}$ is the acoustic wave number and $L_{0}$ is the effective channel length [13]. Recently, several types of space coiling structures have been demonstrated for low-frequency sound attenuation, such as co-planar spiral tubes [60], axially coupled circular tubes [73], coiled air chambers [74], spiral metasurfaces [75], and labyrinthine structures [76-78]. Figure 2a-c shows the various design examples of space coiling metamaterials.

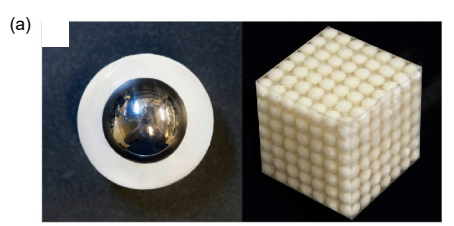

(b)

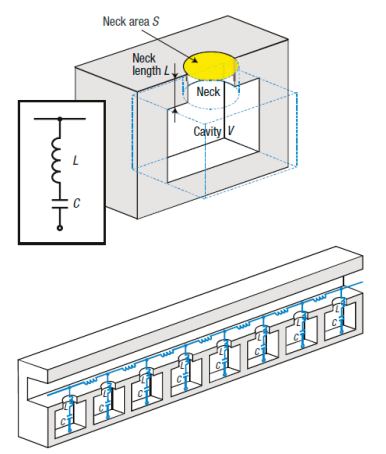

(c)

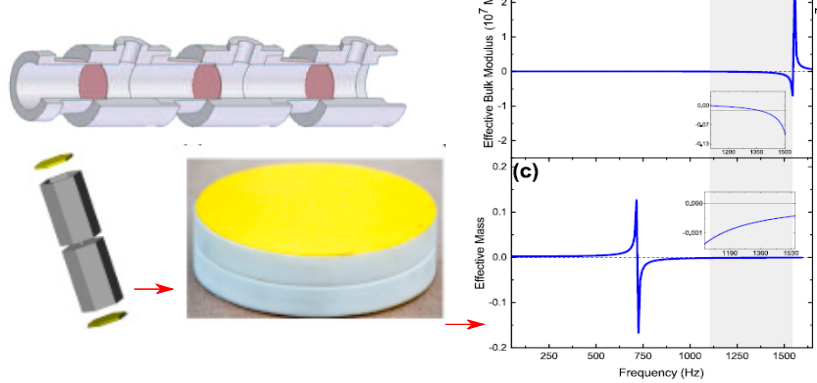

Figure 1. Examples of resonant acoustic metamaterials. (a) Negative mass density $(\rho<0)$ schematic illustrations of sonic crystals and a decorated membrane-type metasurface. Reprinted with permission from Ma et al. [13], (C) 2016 Author(s) under a Creative Commons Attribution Non-Commercial License 4.0 (CC BY-NC), and Yang et al. [44], (C) 2015 Académie des sciences, respectively. (b) Negative effective bulk modulus $(E<0)$ : the Helmholtz resonator unit cell, consisting of a rectangular cavity and a cylindrical neck, filled with water. Reprinted with permission from Fang et al. [45], (C) 2006 Nature Publishing Group. (c) Double negativity $(\rho<0, E<0)$ : the composite structure consisting of interspaced membranes and side holes. Reprinted with permission from Lee et al. [50], (C) 2020 American Physical Society. The double membrane-hexagonal cavity and the dual negative spectra are reprinted with permission from Kumar et al. [79], (C) 2020 AIP Publishing LLC. 
(a)

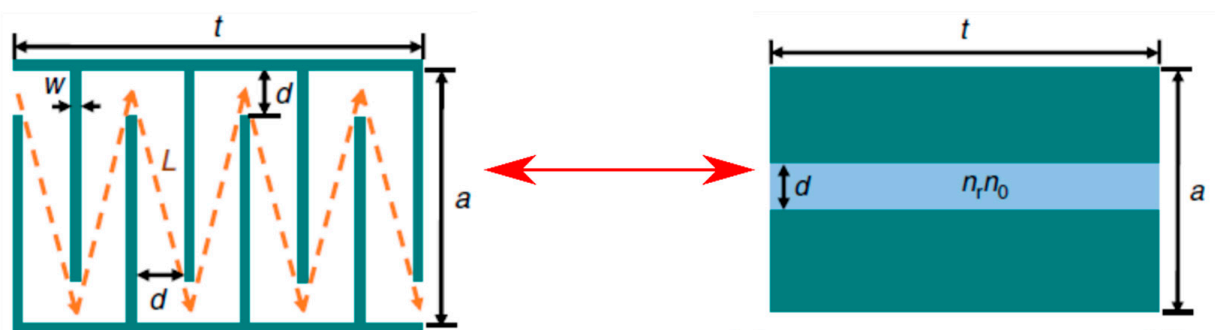

(b)
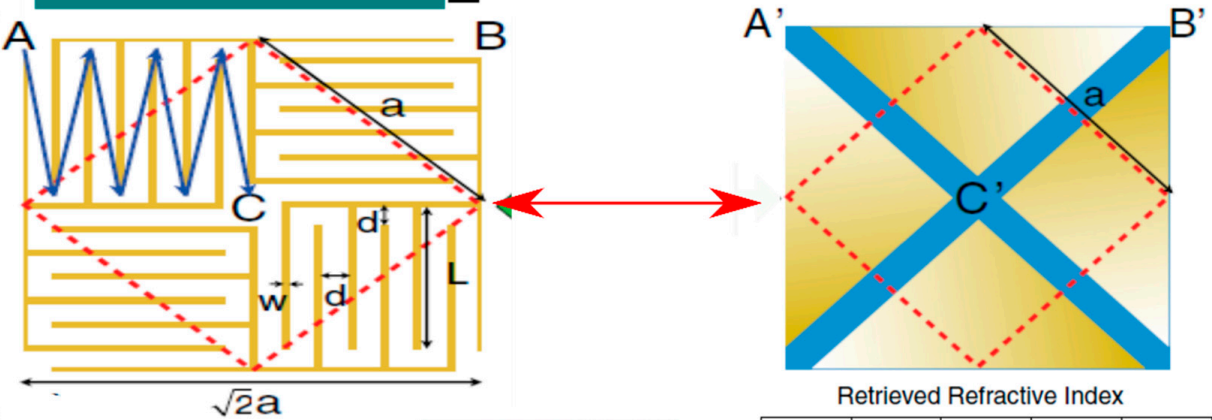

Retrieved Refractive Index
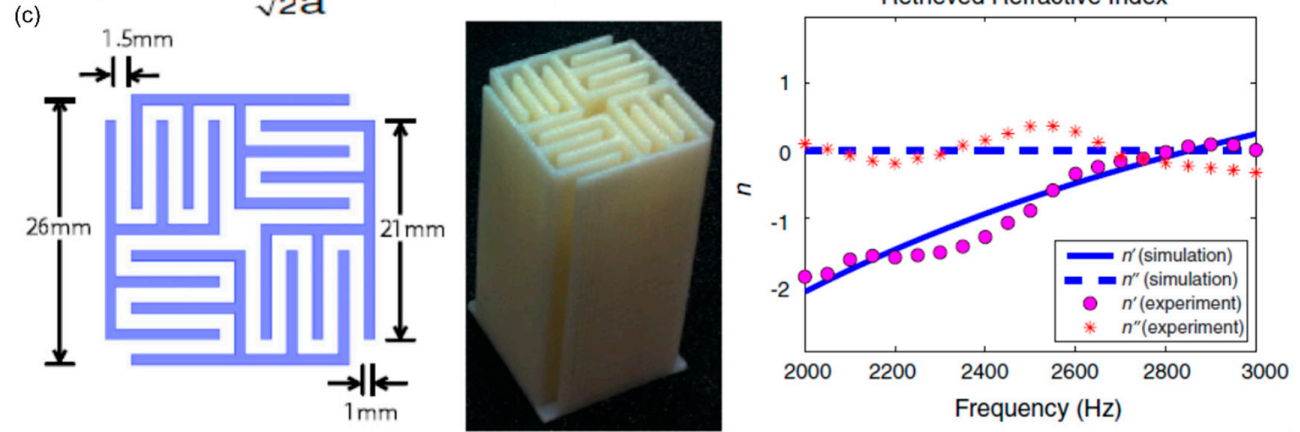

Figure 2. (a) Schematic illustrations of the traditional labyrinthine-type space-coiling metamaterial unit cell with the overall length of $t$ and overall width of $a$. Also, $d$ and $w$ are channel width and coil wall thickness, respectively, and $L$ is the acoustic wave trajectory (represented by the dashed line) length within each coil. The equivalent model featuring a single straight channel filled with a medium of different refractive index is shown. The relative refractive index can be expressed as $n_{r}=L_{e f f} / t$, where $L_{e f f}=N \times L$ is the effective total channel length. Here, $N$ denotes the number of coils. Reprinted with permission from Ghaffarivardavagh et al. [80], licensed under a Creative Commons Attribution 4.0 International License. (b) Schematic diagram of an individual unit of the coiling-up-space metastructure consisting of thin plates of length $L$ and thickness $d$ arranged in folded channels of width $d$ and lattice constant $a$. The zigzag blue arrows denote a path of waves in the second quadrant inside curled channels—-the simplified view with straightened channels (" $X$ "-shaped region). Reprinted with permission from Liang and Li [71], (C) 2020 American Physical Society. (c) The designed labyrinthine unit cell, the photograph of a fabricated unit cell, and the obtained refractive index of the medium. Reprinted with permission from Xie et al. [81], (C) 2020 American Physical Society.

\section{Recent Applications of Acoustic Metamaterials for Sound Attenuation and Ventilation}

\subsection{Acoustic Façade Systems}

Researchers have demonstrated several unique design structures for simultaneous noise attenuation and ventilation. Some traditional technologies, like double-leaf facades and louvers, are quite popular among architects and widely been used in several applications such as buildings (windows, doors, and partitions), heavy machinery cabins, and stations. The conceptual design of the double-skin façade was first proposed and tested by the Swiss-French architect Le Corbusier in the early 20th century [82]. He set an architectural principle popularly known as "the five points of a new architecture". Initially, the double-skin façade design was developed for solar heat comfort for his villa. While the concept of these designs is not new, there is a growing interest in them among designers, 
engineers, and architects because they are lightweight, easy to install, allow clear outer views and natural light, have improved thermal and acoustic insulation, and provide natural ventilation and fresh air circulation. In recent times, double-leaf facades have become favored as transparent window panels in skyscraper buildings. The multiple wall facades windows have now been designed and customized for attaining simultaneous noise insulation and natural ventilation. Bajraktari et al. [83] investigated the acoustical performance of double-leaf facades. The structure consisted of two face sheets, namely primary and secondary facades, with the ventilated openings. These face sheet openings were positioned at particular locations so that the incoming sound and the air entered from the source side and circulated in the intermediate cavity before passing to the other side of the facade. Figure $3 a$ shows the arrangement of a double-leaf façade system. The sound reduction index of 27 to $35 \mathrm{~dB}$ was achieved from these double facade systems. Such high sound insulation was achieved due to the frictional resistance offered by the ventilated openings, and the impedance mismatch resulted from the air cavity between face sheets. Moreover, by carefully adjusting the location of window openings and the spacing between the face sheets, the sound insulation performance can be tuned. Zuccherini Martello et al. [84] modified the traditional building façade system for the enhancement of acoustical performances. A thin layer of sound-absorbing material was stacked underneath the metal lightweight louvers and investigated their sound reduction performance. Figure $3 \mathrm{~b}$ shows the photographs of the louvers installed for the noise measurement and the absorptive material (polyurethane conglomerate) that was used with the louvers.

A modified design of the double-glazing façade systems known as plenum window panels has also shown capabilities for noise insulation (especially the traffic noise) with proper ventilation for light and air in high-rise buildings. The plenum window panels consist of at least two face sheets with the staggered inlet and outlet openings. These are designed in the zigzag configuration to block the direct sound path from the outdoor to the indoor environment while allowing natural ventilation across it. Several researchers, including our research groups, have made significant progress in this regard [85,86]. Tang [87] investigated the sound transmission loss performances of plenum windows. A standard double-leaf façade window was modified by installing rigid circular cylinder arrays into the air gap cavity. Figure $3 \mathrm{c}$ illustrates the schematics of the plenum window and different schemes of cylindrical arrays orientations. The cylinder positions were relative to the nodal/anti-nodal planes of the incoming acoustic modes, resulting in an overall improvement of sound transmission loss values of around $4-5 \mathrm{~dB}$ compared to the standard plenum window panels. However, installing such rigid cylinders in the air cavity may obstruct the airflow. Recently, Li et al. [88] attempted to establish simple empirical models for predicting transmission loss performance across plenum windows. A total of fourteen full-scale plenum windows were included in the study, and their parametric analysis was performed. The model was validated through the ensuing experiments. Lee et al. [89] incorporated sonic crystals with the existing standard plenum windows and their acoustical performance was investigated. Figure $3 \mathrm{~d}$ shows the experimental reverberation room set-up of the plenum windows with two different settings. The dimensions of the sonic crystals were selected with the target central frequency of $1000 \mathrm{~Hz}$ and a resonant frequency of $1164 \mathrm{~Hz}$. It was revealed that the incorporation of sonic crystals with the plenum window panels resulted in additional attenuation of $4.2 \mathrm{dBA}$ and $2.1 \mathrm{dBA}$ of traffic and construction noises, respectively, at $1000 \mathrm{~Hz}$. Although sonic crystals have been proven to be a good acoustic barrier for traffic and construction noises, these structures require a larger space for their installations. 
(a)
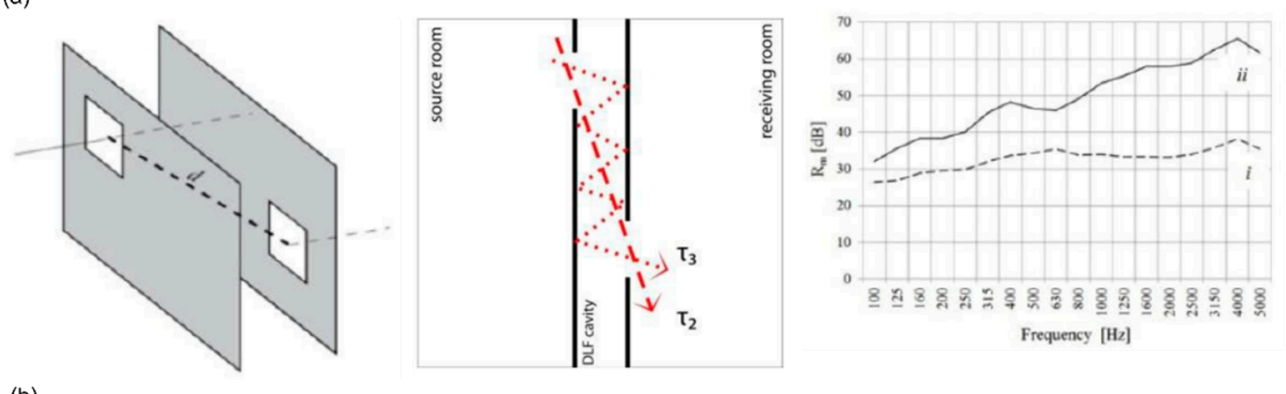

(b)
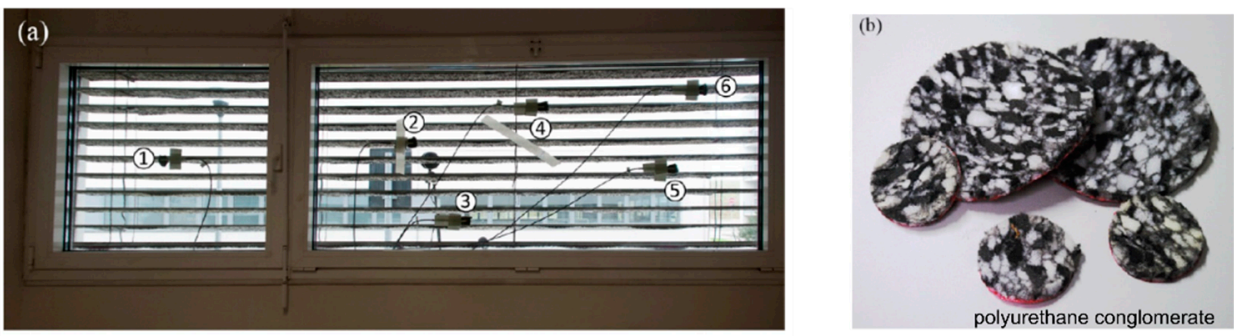

(c)
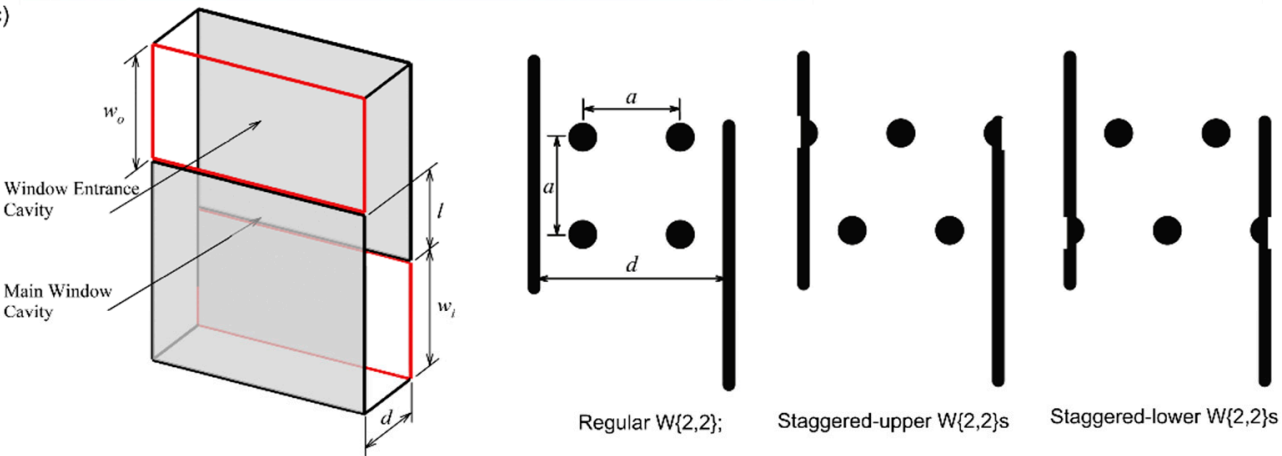

Regular W\{2,2\}; Staggered-upper W\{2,2\}s Staggered-lower W\{2,2\}s

(d)
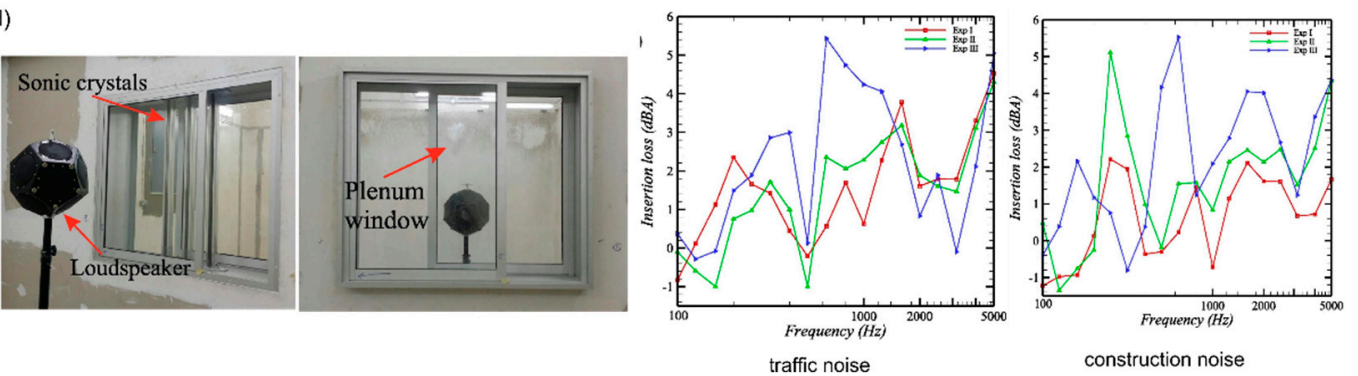

Figure 3. (a) Schematic illustrations of the double-layered façade system with openings and the measured sound reduction index ( $\mathrm{Rm}$ ) of the experimental wall (i): one layer fully closed and one fully open; (ii): both layers fully closed). Reprinted with permission from Bajraktari et al. [83], (C) 2020 Elsevier Ltd. Licensed under the CC BY-NC-ND license. (b) Photographs of the measurement set-up of the installed glazed surface and the absorptive material (polyurethane conglomerate) used with the louvers. Reprinted with permission from Zuccherini Martello et al. [84], (C) 2020 by the authors; licensee MDPI, Basel, Switzerland. (c) Schematics of a plenum window unit and the orientations of cylinder arrays relative to the plenum window cavity; regular, staggered-upper, and staggered-lower windows. Reprinted with permission from Tang [87], (C) 2020 Elsevier Ltd. (d) Experimental reverberation room set-up of the plenum windows with two different settings and the measured insertion loss spectra under traffic noise and construction noises. Reprinted with permission from Lee et al. [89], (C) 2020 Elsevier Ltd.

\subsection{Helmholtz Resonators}

Helmholtz resonators are conventional devices that have been widely used for the enhancement of acoustic wave energy absorption. A typical Helmholtz resonator consists of a known volume 
rigid wall air cavity and a narrow neck. The fluid present in the neck area acts approximately as a mass, whereas the compressible fluid in the rigid cavity acts as a spring. It can be considered as a spring-mass system. When sound pressure waves enter the neck, this displaces the air down to the neck, causing the air inside the cavity to be compressed. At the resonant frequency, the compressed air inside the cavity propels against the incoming sound wave (equivalent to spring displacement in the spring-mass system), thus realizing a dynamic response from the system known as the effective negative bulk modulus. The resonant frequency of the Helmholtz resonator is given as $f_{h}=\frac{c}{2 \pi} \sqrt{\frac{A}{V L_{e f f}}}$, where $c$ is the speed of sound in the air, $A$ is neck cross-sectional area, $L_{e f f}$ is the corrected neck length, and $V$ is the volume of the cavity. Also, the effective bulk modulus, which is the ratio of pressure drop in the neck to the change in volume in the cavity, can be calculated from the following [45]: $E_{e f f}(\omega)=E_{0}\left[1-\frac{F \omega_{h}{ }^{2}}{\omega^{2}-\omega_{h}{ }^{2}+i \Gamma \omega}\right]^{-1}$, where $E_{0}$ is the bulk modulus of the air, $F$ is the geometrical factor, and $\Gamma$ is the dissipation loss factor. In the past two decades, the Helmholtz resonator's concept has been widely incorporated into the development of acoustic metamaterials.

Kim and Lee [90] presented a prototype of air transparent soundproof window panels. As shown in Figure 4a, the structure consisted of a three-dimensional array of robust diffraction-type resonators with individual central holes with subwavelength diameter. While the resonator and the central hole together resulted in the effective negative bulk modulus at a particular frequency, at the same time, the central though-holes paved the way for air ventilation. Using the design concept, average sound reduction was achieved of about $20-35 \mathrm{~dB}$ in the frequency range of $400 \mathrm{~Hz}-5000 \mathrm{~Hz}$. The measured transmission loss spectra showed a reduction in sound wave amplitudes because of the realization of the negative effective bulk modulus. Wang et al. [91] investigated the acoustical performances of multiple ventilated window panels with quarter-wave resonators and a membrane absorber. Figure $4 \mathrm{~b}$ illustrated the proposed designs. For the efficient transmission of environmental light into the buildings, the transparent plexiglass plastic sheet was used to fabricate these acoustic silencers. The high transmission loss of 10-22 dB from the designed acoustic window panels was achieved in a $500 \mathrm{~Hz}-4000 \mathrm{~Hz}$ frequency range. Also, the outlet airflow velocity of the ventilated window design was found to be higher than that of a standard open window. Yu et al. [92] performed theoretical investigations on the sound insulation performance of the proposed planer acoustic metasurface. The structure design was an array of multiple unit cells, and each unit cell consisted of a central air duct with periodic sub-wavelength resonators. A finite element based theoretical and numerical approach was used to evaluate the sound characteristics in the frequency range of $125 \mathrm{~Hz}$ to $2000 \mathrm{~Hz}$. Jung et al. [93] demonstrated an acoustic metamaterial panel for both fluid passage and broadband soundproofing in the audible frequency range of $2000 \mathrm{~Hz}$ to $4000 \mathrm{~Hz}$. The unit cell of the panel consisted of a circular through duct enclosed with multiple annular circumferential cavities. The circular hole made a provision for continuous fluid passage, while the equidistant annular cavities were associated with the noise reduction because of their Helmholtz resonance effects. More recently, Kumar et al. [94] presented ventilated acoustic metamaterial window panels for simultaneous noise shielding and air ventilation. The metamaterial unit cell was composed of a square-shaped central ventilated hole, and a Helmholtz chamber with two square-shaped necks on the inner sidewall (Figure 4c). The experimental results showed the proposed design's abilities to achieve significant narrowband noise attenuation in the low-to-mid frequency range while providing substantial ventilated space for air passage. They also presented a proof-of-concept for scaling-up of the small unit cell for large-space noise insulation. A simple jigsaw puzzle-like assembly technique was demonstrated to interconnect the multiple unit cells, which led to the production of an integrated acoustic architecture without further adhesives. Wang et al. [95] experimentally investigated the acoustic performances of a perforated and constrained acoustic metamaterial (PCAM). The presented structure, eventually a part of the plate-type acoustic metamaterial category, was composed of the perforated plate and a rigid supporting frame. The rigid frame was composed of multiple unit cells, and each unit cell contained an orifice at the center, allowing for air circulation. The top thin perforated plate was stacked over the rigid frame in the final structure. 
Figure $4 \mathrm{~d}$ shows the illustrative configuration of the perforated and constrained acoustic metamaterial (PCAM). The results revealed the ability of sound insulation of tonal noises in a low-frequency noise regime $(<500 \mathrm{~Hz})$. The metamaterial possessed high transmission loss performance with a maximum transmission loss peak of $\sim 25 \mathrm{~dB}$ at $430 \mathrm{~Hz}$ and a large perforation ratio. Such high noise insulation originates from sufficient interferences between the two wavefields at the orifice and the plate regions.
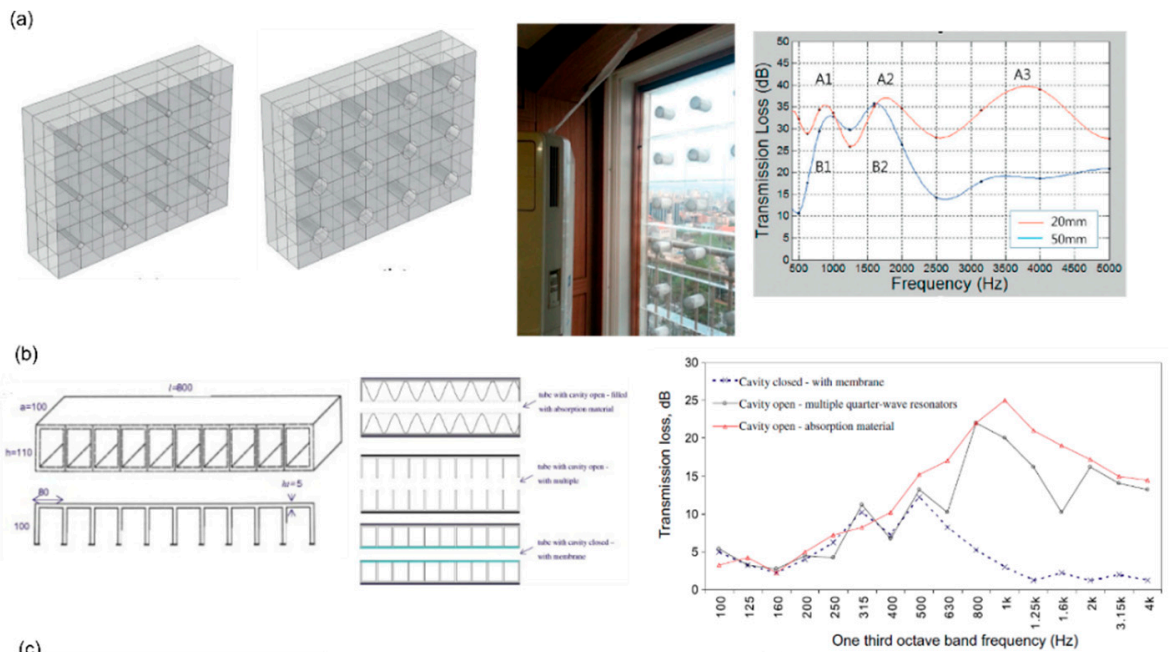

(c)

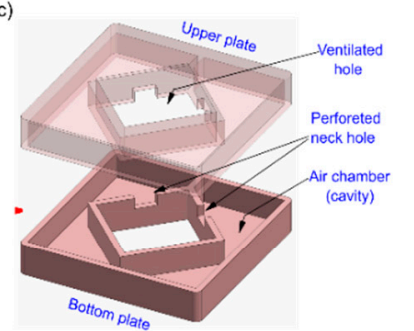

(d)
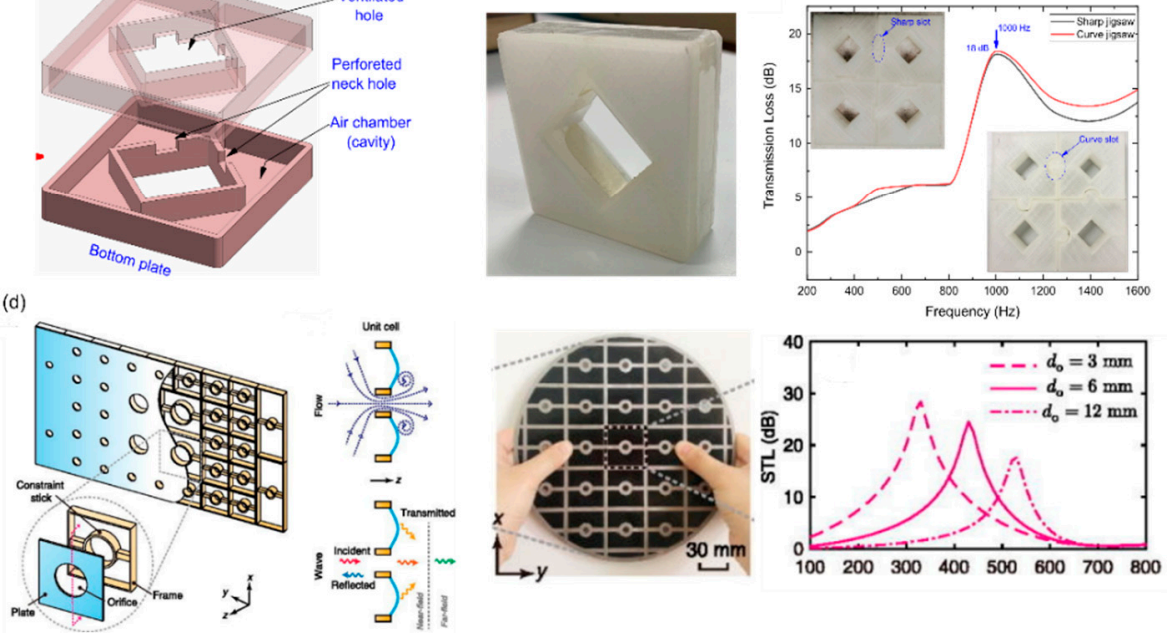

Figure 4. (a) Schematics of the proposed air transparent acoustic window panels (consisting of transformed resonators and air filters with hole diameters of 20 and $50 \mathrm{~mm}$. The dimensions of each cell were $150 \mathrm{~mm} \times 150 \mathrm{~mm} \times 40 \mathrm{~mm}$ with a thickness of $5 \mathrm{~mm}$ of a transparent acrylic sheet). Photographs are of the installed window panel in building and their measured transmission loss spectra, which was about 30-35 dB in the range of 400-5000 $\mathrm{Hz}$ with the $20 \mathrm{~mm}$ window and about $20-35 \mathrm{~dB}$ in the range of 700-2200 Hz with the $50 \mathrm{~mm}$ window. Reprinted with permission from Kim and Lee [90], (C) 2014 Author(s), licensed under a Creative Commons Attribution 3.0 License. (b) 3D-view and top-view of the multiple quarter-wave resonators. Measured transmission loss spectra of three types of silencers are shown. Reprinted with permission from Wang et al. [91], (c) 2013 Elsevier Ltd. (c) Schematic details of ventilated metamaterial unit cell composed of two necks and a single chamber. A maximum transmission loss peak of around $18 \mathrm{~dB}$ was achieved from the proposed design. Reprinted with permission from Kumar et al. [94], (C) 2019 Elsevier Ltd. (d) Typical configuration of the perforated and constrained acoustic metamaterial and the measured transmission loss spectra. Reprinted with permission from Wang et al. [95], (C) 2019 AIP Publishing LLC. 


\subsection{Noise Attenuation Through Coiling-Up-Space}

Space-coiling metastructures contain acoustic channels with subwavelength dimensions in the confined space. Various designs like labyrinthine, spiral, curved, folded chains, and helix have been utilized for the development of these metastructures. The unusual acoustic properties like the refractive index have resulted from these engineered structures, capable of effectively slowing down the sound speed and reducing sound intensity because of the frictional resistance offered at the air-channel wall interface. When the sound wave enters into the metastructure, it propagates along the coiled path, which is considerably longer than the structure's physical dimensions (see Figure 5). The longer path length allows the modulation of reflected sound waves and the reflected phase shift to be customized within the full $0-2 \pi$ range. The concept of space coiling has been utilized in many applications such as lenses, waveguides, and absorbers. Recently, Yang et al. [96] presented a holey acoustic metamaterial panel for low-frequency sound attenuation. The unit cell of the designed metastructure consisted of two adequately spaced thin panels with a square hole at the center, and a specifically designed rigid partition inserted between the holey panels. As illustrated in Figure $5 \mathrm{a}$, two different variants of partitions, namely the 'quarter model' and 'half model', were used in the experimental investigations. Each type of partition model was equipped with a central square opening and the slotted 'L-shape' waveguides. While the central hole in the metamaterial panel allowed uninterrupted fluid flow, the rigid partition structure influenced noise insulation by slowing the incoming sound wave speed into the subwavelength gap between the L-shaped slots. The results suggested the broadband transmission loss from $1400 \mathrm{~Hz}$ to $2500 \mathrm{~Hz}$ with a transmission loss peak of around $30 \mathrm{~dB}$ in the case of the quarter-model metapanel. Also, the enhanced transmission loss bandwidth for the half-model unit cell was observed in a relatively low-frequency range between $730 \mathrm{~Hz}$ to $1350 \mathrm{~Hz}$, with a maximum transmission loss peak of around $18 \mathrm{~dB}$. Such efficient soundproofing properties were obtained from the thin metapanel of thickness around $18 \mathrm{~mm}$. Zhang et al. [97] realized a ventilated omnidirectional acoustic barrier. The metasurface was composed of multiple arrays of two different unit cells; first, a labyrinthine-based coiled unit cell for sound shielding, and second, a hollow pipe providing continuous fluid ventilation. The labyrinthine-based coiling-up structure enables sound propagation with a phase delay of $2 \pi$ within a sub-wavelength domain, resulting in a high sound transmission loss. Yu et al. [98] demonstrated the acoustical performances of the acoustic metamaterial grating. The metamaterial unit cell consisted of an open channel patterned with an array of space-coiling resonators intended to attenuate sound transmission using its acoustic stop-band. The subwavelength size of the coiled resonators allowed sound attenuation in the low-frequency band. The results obtained from the structures showed their potential for use as ventilated acoustic barriers. Ghaffarivardavagh et al. [99] demonstrated the use of the ultra-open (i.e., ventilated) acoustic metasurface for silencing of low-frequency noise. The ring-shaped metasurface unit cell consisted of a helical structure in the periphery and a completely open area at the central portion, which was equivalent to $60 \%$ of the total cross-sectional area of the metamaterials. Figure $5 \mathrm{~b}$ shows the schematic illustration of the proposed metastructure. The central open area yielded a high degree of air transport, while the circumferential helical cavities enabled the noise silencing. The reduction in the incoming acoustical energy at targeted frequencies resulted from the acoustic refractive index mismatch between the open area (air) and the helical structure. The helical structure of multiple helix channels in transverse orientation provided the extended path length of the acoustic wave, which resulted in a broad effective refractive index in the region. The cross-sectional area of the helix channels was kept smaller than the waveguide, which yielded a significant acoustic impedance mismatch. As shown in Figure 5b, the designed acoustic metamaterial was able to reduce the transmitted acoustic energy of up to $94 \%$ in the low-frequency regime $(\sim 460 \mathrm{~Hz})$. Sun et al. [100] demonstrated the acoustic ventilation barriers of planer-profile with subwavelength thickness for the sound barrier in a broad range. Figure $5 \mathrm{c}$ shows the schematics of a helical meta-unit cell. The structure was composed of two parts: the central hollowed-out orifice and a surrounding helix pathway with varying pitch. The proposed hornlike helical metasurface achieved simultaneous broadband sound reduction and significant airflow passage. 
The broadband sound insulation realized between the monopolar and the dipolar mode responses originated from the helix structure. The frequency range of these responses can be adjusted by tuning the helical pathway's pitch. The hornlike helical pathways provided excellent flexibility for tailoring of the acoustic waves, and their monopolar and dipolar mode responses resulted in high noise insulation of around $90 \%$ of incident energy in the range of $900-1418 \mathrm{~Hz}$.
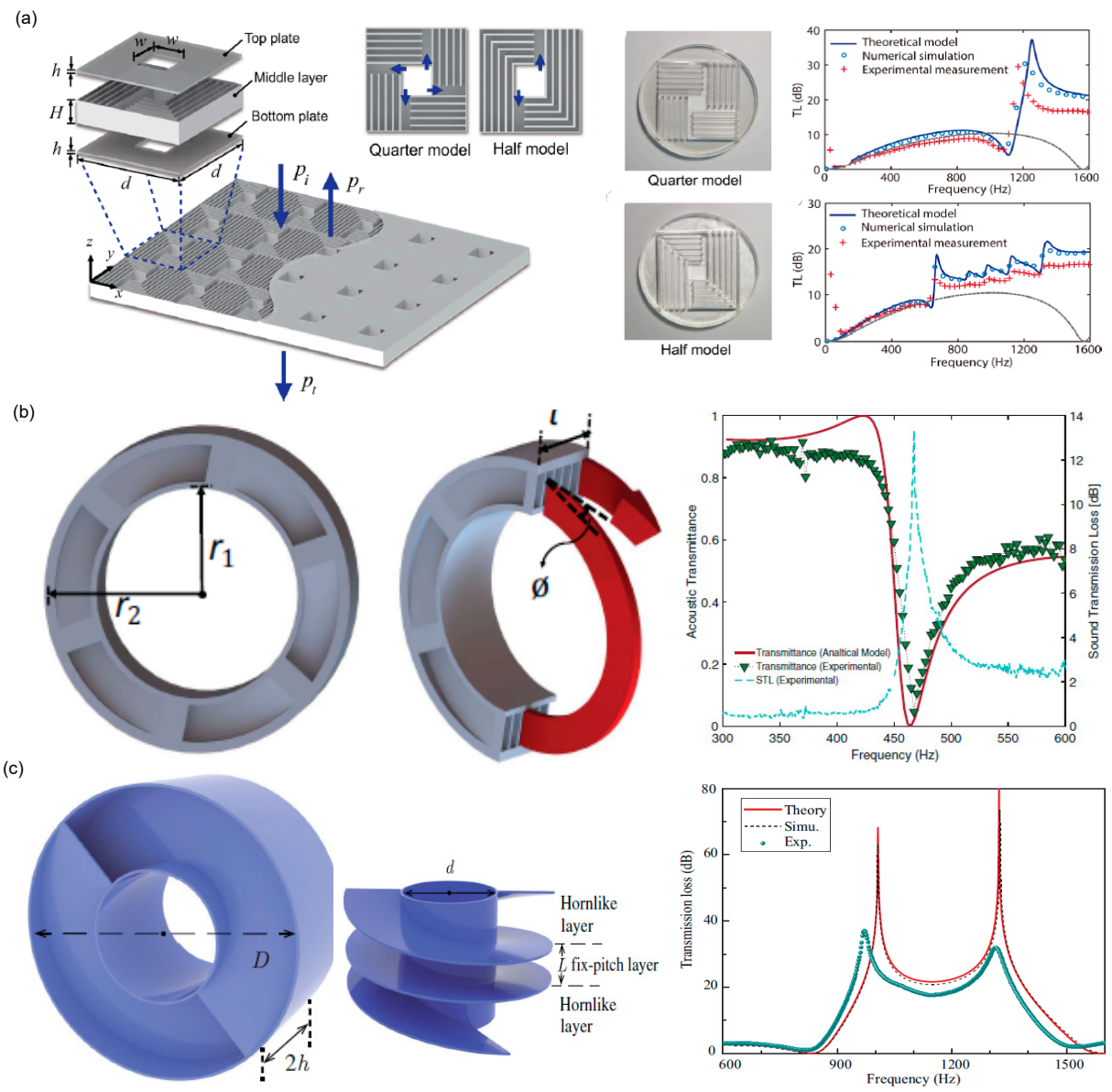

Figure 5. (a) Schematic diagram of the slow-wave metamaterial open panel composed of periodically repeated subwavelength unit cells. Photographs of 3D printed samples (12 $\mathrm{mm}$ thickness) and their corresponding transmission loss spectra are shown. Reprinted with permission from Yang et al. [96], (c) 2018 AIP Publishing LLC. (b) Schematics of the ultra-open metamaterials composed of the central open region and the transverse bilayer structure, featuring six channels coiled in the helix form. The simulated (solid red line) and experimental (dotted green line) acoustic transmittance spectra with the measured sound transmission loss spectrum (dashed blue line) are shown. Reprinted with permission from Ghaffarivardavagh et al. [99], (c) 2020 American Physical Society. (c) Schematics of a helical meta-unit cell composed of two parts: the central hollowed-out orifice and the surrounding helix and transmission loss spectra of the helical meta unit, theoretical (red line), simulated (black dashed line), and measured (green dots). Reprinted with permission from Sun et al. [100], (C) 2020 American Physical Society.

\subsection{Acoustic Metacage}

"Acoustic metacage" refers to the shielding of noise by installing the acoustic metamaterials-made cage around either the source or the receiver. If the sound originates from the confined source, then it is always recommended to install the acoustic metastructure around it. Recently, Shen et al. [101] presented a unique design of a ventilated acoustic metacage for sound shielding and steady fluid flow. The circular-shaped structure was designed based on an acoustic gradient-index metasurface 
composed of open tapered channels and shunted Helmholtz resonators. Figure 6a shows the schematic illustrations of a ventilated metacage and photograph of the 3D printed metacage. The dimensions of the unit cell were tailed to ensure that the supercell covers a complete $2 \pi$ phase delay. The structure provided almost uniform sound shielding from all incident angles. The fabricated metacage was capable of achieving a sound transmission loss of around $10 \mathrm{~dB}$ within the frequency range of 2.2 to $2.6 \mathrm{kHz}$ with a simultaneous fluid flow of velocity $1 \mathrm{~m} / \mathrm{s}$. Also, no significant change in sound performance was observed under the fluid flow. This is because the fluid flow rate $(1 \mathrm{~m} / \mathrm{s})$ was much smaller than the sound speed in air ( $343 \mathrm{~m} / \mathrm{s})$. Recently, Melnikov et al. [102] demonstrated the capabilities of acoustic metamaterials for the reduction of stage machinery noise. The three-dimensional meta-capsule design prototype was used to investigate the acoustical performance of the stage machine component. The metamaterial cuboid capsule was composed of an array of equidistant C-shape meta-atoms in three sidewalls, and the absorbing pads in two sidewalls and a rigid bottom plate. The schematic diagrams of a C-shaped meta-atom unit cell and the integration strategy for noise shielding are shown in Figure $6 \mathrm{~b}$. The C-shaped hollow tubes can be equivalent to the Helmholtz resonators and are accountable for the noise attenuation, while the air gap between two meta-atoms allowed the unrestricted airflow for the cooling of the machine components.

(a)

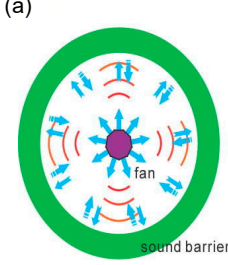

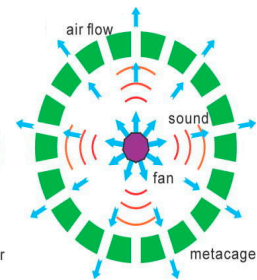
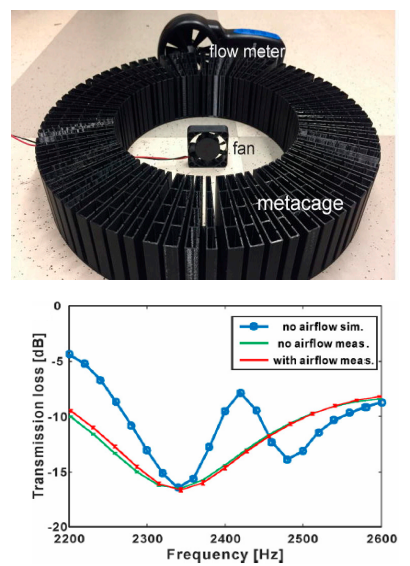
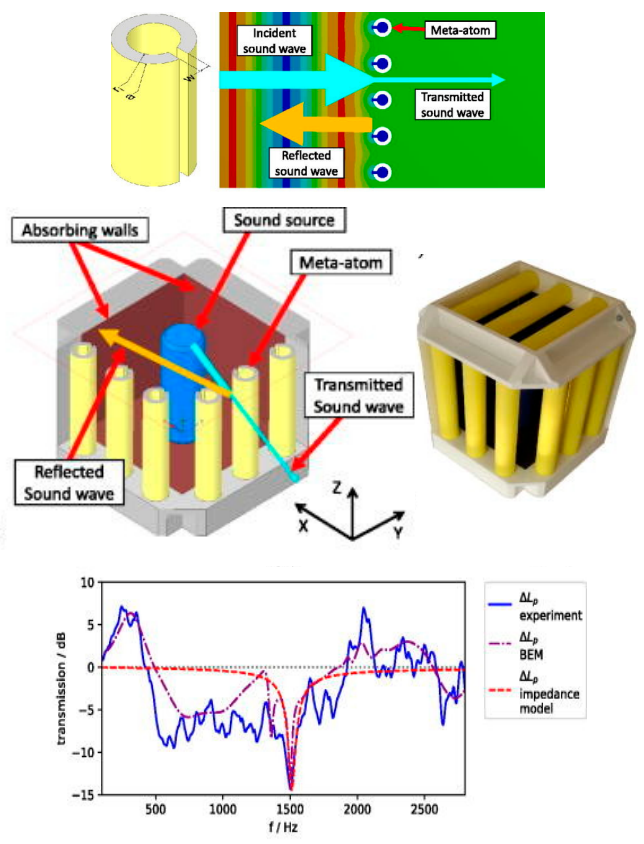

Figure 6. (a) Schematics of the proposed acoustic metacage design. Reprinted with permission from Shen et al. [101], (C) 2020 AIP Publishing LLC. (b) Schematic representations of the C-shaped meta-atom unit cells and proposed meta-capsule prototype concept: the sound wave is redirected by the meta-grating to the absorbing walls. The manufactured meta-capsule and the transmission spectra of the meta-capsule (simulated and experimental) are depicted. Reprinted with permission from Melnikov et al. [102], licensed under a Creative Commons Attribution 4.0 International License.

\subsection{Acoustic Meta-Absorbers}

The acoustic meta-absorber is a special kind of acoustic metamaterial capable of providing high sound absorption in a targeted frequency range. The low-frequency sound absorption of the metastructures has mainly been achieved by employing the concept of impedance matching, which enhances the coupling of the incident acoustic energy with the absorbers [13]. The acoustic impedance matching with air implies no reflection from the sound-absorbing metastructure, ensuring the maximum absorption of sound energy inside the structure. Since the inception of acoustic metamaterial concepts, a variety of meta-absorbers with subwavelength-scale structures have been 
realized. These structures include decorated membrane resonators, hybrid resonators, degenerate resonators, coiled Fabry-Perot, coherent perfect absorption, and Helmholtz resonators. For a more detailed description of acoustic metamaterials' sound-absorbing fundamentals, one can follow the previously published review article by Yang and Sheng [103]. The effectiveness and simplicity of the acoustic meta-absorbers have resulted in them gaining considerable attention. In recent years, several acoustic metastructures have been presented for sound absorption and airflow purposes. Lee et al. [104] presented the absorption-type metamaterials with an ultrahigh sparsity. The sparse acoustic absorber was composed of a periodic array of two-sided Helmholtz resonators (HRs) that permitted fluid flow and light propagation while insulating the incoming sound. They demonstrated two different types of sparse absorber design, the fish shape and double-diamond shape, for simultaneous fluid flow manipulation and optical cloaking, respectively, along with the absorption of sounds. Figure 7a shows the photographs of 3D-printed sparsely arranged acoustic absorbers of both types. They experimentally realized that the sparse absorber array exceeded $90 \%$ absorption at the resonance frequency of $2200 \mathrm{~Hz}$ with a volume-filling ratio of approximately $26 \%$. Also, the ultrasparse acoustic absorber had shown the excellent tunability for the air-flow-direction control and optical cloaking. A similar kind of sparse absorber has also been demonstrated by Lee et al. [105]. As illustrated in Figure 7b, the meta-absorber consisted of an array of dual resonance unit cells. Each unit cell consisted of two resonators. The upstream resonator is partially filled with foams, and the downstream resonator has an empty hollow cavity with a neck. The dimensions of both these resonators were chosen for the constant operating resonant frequency. The experimental results showed a high absorption bandwidth of $900 \mathrm{~Hz}$ obtained from the proposed metamaterials. Such a high bandwidth was obtained due to the addition of loss media, i.e., foams in the sparse absorbers' design.

These design prototypes have shown efficient sound absorption capabilities in the higher frequency range. Low-frequency sound absorption while maintaining efficient air ventilation remained a challenge. In recent years, a few designs have been demonstrated in this regard. Li et al. [106] demonstrated a broadband and compact acoustic absorber with high-efficiency ventilation performance. The metastructure was constructed with eight-unit cells arranged in the square periphery that resulted in a large central open space for air ventilation. The ratio between the ventilated area and overall cross-sections was kept around $70 \%$. The individual unit cell consisted of a double-layered metastructure perforated with arrays of deep-subwavelength micro-perforations on two opposite sides. The multiple perforation-sized holes were used for the designated target frequencies. The results reported an average absorption coefficient above 0.5 in the frequency range of 850 to $1000 \mathrm{~Hz}$.

Keeping the aim for the low-frequency sound absorption, Wu et al. [107] demonstrated a highly efficient ventilated acoustic metamaterial absorber (VMA) at a low-frequency regime $(<500 \mathrm{~Hz})$. The VMA was composed of multiple layers of absorption unit cells. Each absorber unit was comprised of two identical but oppwositely oriented split tube resonators. The high-efficiency sound absorption $(>90 \%)$ had been achieved by using two layers of the absorber units. Such a high absorption was realized due to the weak coupling of two identical split tube resonators. Also, the gap between the two absorber units was provided for ventilation purposes. Kumar and Lee [108] demonstrated the labyrinthine acoustic metastructures for broadband sound absorption and efficient ventilation. As shown in Figure $7 \mathrm{c}$, the metastructure had orchestrated six labyrinthine unit cells of different configurations in a hexagonal array. The subwavelength metastructure exhibited a superior sound absorption with a high bandwidth (more than one octave in the range of 400-1400 Hz). Such a broadband absorption was achieved by the dissipation of incident sound waves between the labyrinthine zigzag channels, while the central opening facilitated natural ventilation. The acoustic performance of the presented acoustic metastructures can be customized as per the requirements. More recently, Xiang et al. [109] demonstrated an ultra-open ventilated metamaterial absorber (UVMA). The absorber was comprised of weakly coupled split-tube resonators, which resulted in a simultaneous high-efficiency absorption and ventilation. Figure $7 \mathrm{~d}$ shows the schematic of the UVMA units arranged in a rectangular lattice. The realization of high broadband sound absorption through the meta-absorbers resulted from the 
small coupling between the two split-tube resonators, which led to the merging of the resonance peaks of the symmetric and anti-symmetric modes.

(a)

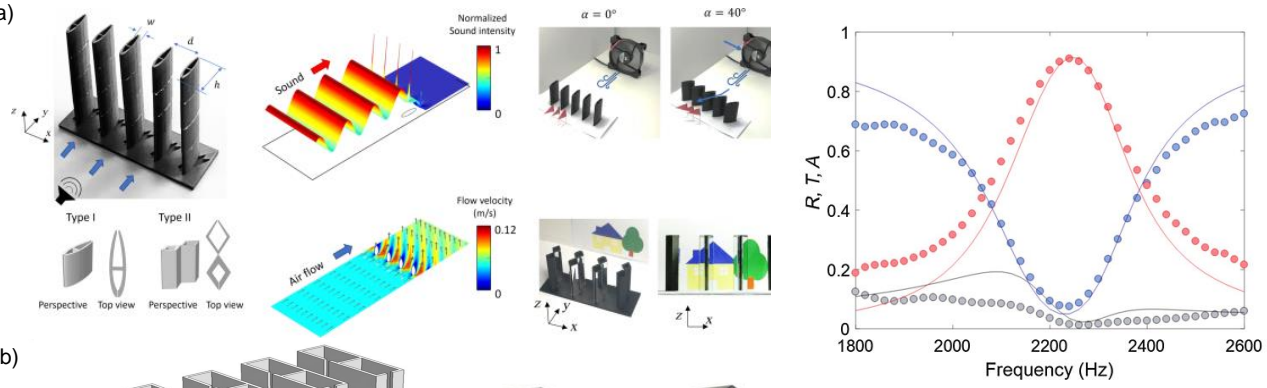

(b)
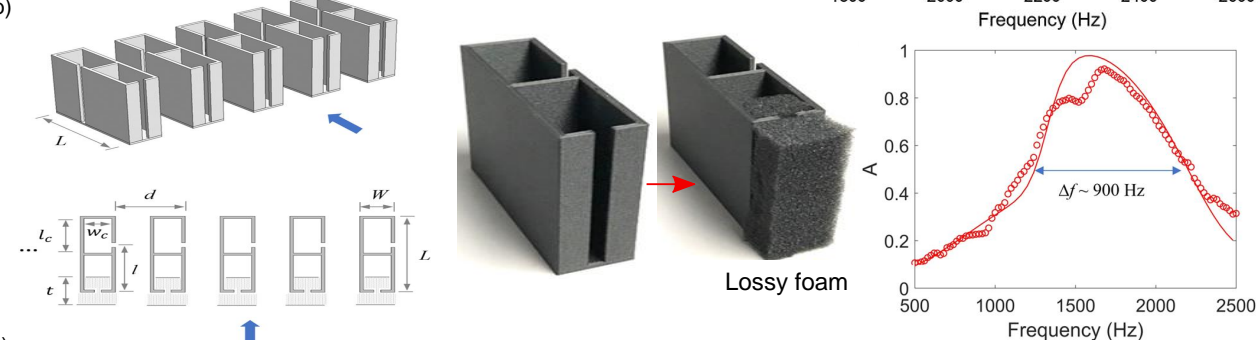

(c)
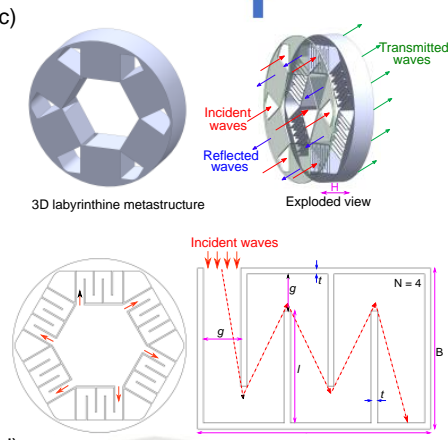

(d)
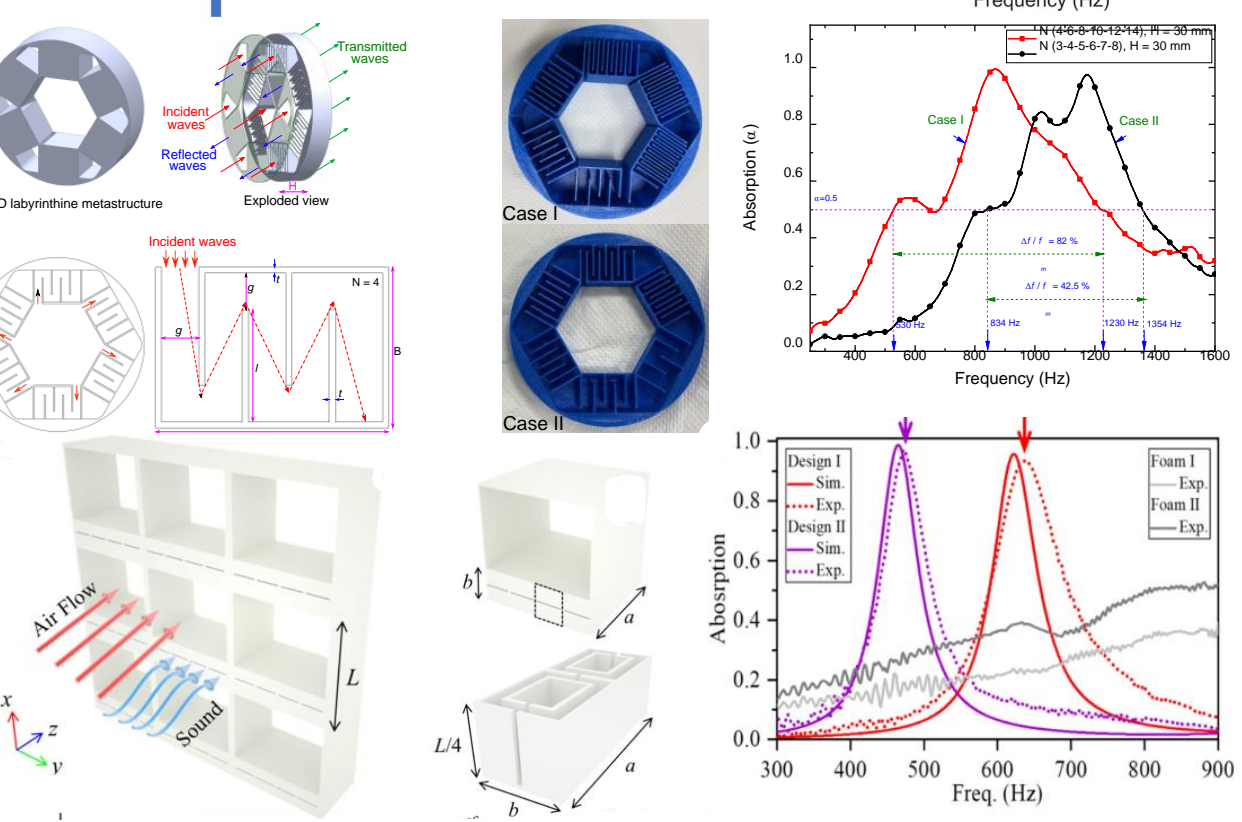

Figure 7. (a) Photographs of the multifunctional sparsely arranged acoustic absorbers (Type I: fish shape, Type II: double-diamond shape). Corresponding measured acoustic spectra (symbols) for the HR pair array are shown. Reprinted with permission from Lee et al. [104], (c) 2020 American Physical Society. (b) Schematics and photographs of the broadband sparse absorbers composed of dual-resonance Helmholtz resonators and measured absorption spectra of the sparse absorbers (right side). Reprinted with permission from Lee et al. [105], licensed under a Creative Commons Attribution 4.0 International License. (c) Schematic representation of the labyrinthine acoustic metasurface with an exploded view. The photographs of 3D printed samples with two different design types and their corresponding experimental results of broadband sound absorption spectra (right side) are shown. Reprinted with permission from Kumar and Lee [108], @ 2020 AIP Publishing LLC. (d) Schematic of the UVMA units arranged in a rectangular lattice and close-up views of single supercells comprised of four UVMA units. Simulated (colored solid lines) and experimentally measured (dotted lines) absorption spectra of different designs are shown. Gray solid lines represent the measured absorption spectra of melamine foams. Reprinted with permission from Xiang et al. [109], (c) 2020 Elsevier Ltd. 


\subsection{Omnidirectional/Unidirectional Sound Insulators}

In recent times, acoustic metamaterials have been employed for uni/omnidirectional sound wave propagation. Based on these design concepts, an acoustic waveguide can also be designed whose transmission property can be freely switched between all possible directions. These unique concepts have great potential for utilization in the development of ventilated acoustic window panels. Ge et al. [110] demonstrated the unidirectional and omnidirectional acoustic insulation through an open window structure with a metasurface of ultrathin hook-like meta-atoms (Figure 8). The acoustic metasurface design also was capable of switchable acoustic wave insulation directions [111]. The omnidirectional acoustic insulation could be switched 'on' or 'off' by adjusting the distance between two adjacent blades.

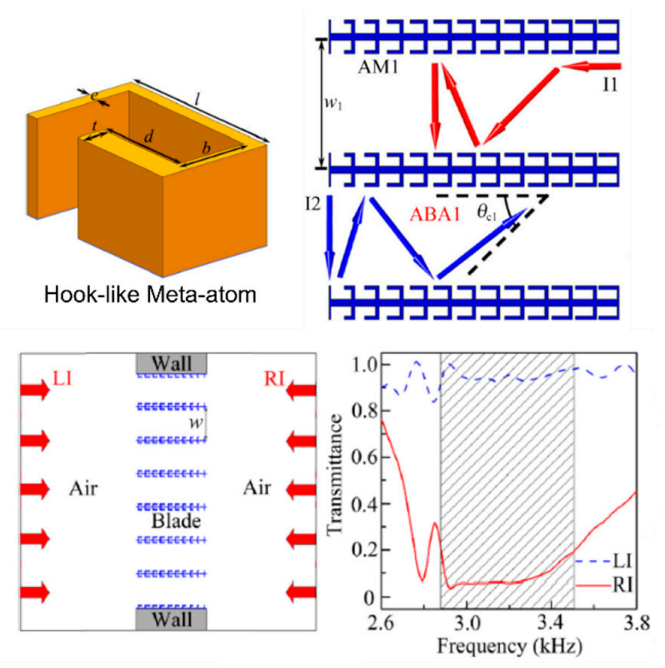

Figure 8. Schematics of a hook-like meta-atom, acoustic propagation paths through the open windows with left incidence LI and right incidence RI, and corresponding transmission spectra. Reprinted with permission from Ge et al. [110,111], (C) 2018 AIP Publishing LLC and (C) 2019 American Physical Society, respectively.

\section{Outlook}

The last decade has witnessed tremendous growth in acoustic metamaterials research fields. From the physics-based theoretical/numerical modeling to the experimental investigations, and from prototype design to large-scale fabrications, researchers have demonstrated the extraordinary competences of acoustic metamaterials for many applications, and in particular, low-frequency noise mitigation. However, ongoing research can be extended into the following directions:

I. Design methodologies. The acoustic metamaterials are artificially engineered structure-based composites containing complex and sophisticated designs. The unusual characteristics, like the negative effective mass density and negative effective bulk modulus, stem from their geometry and structure rather than the material composition of which they fabricated [112]. Therefore, the physics-based geometrical design is a crucial step for the development of specific acoustic metastructures. The current metamaterial research steps include physics-based modeling, numerical simulations, 3D printing, and acoustical measurements. The researchers often face several challenges related to designing a specific structure for the desired targets. Sometimes, they need to go through several hit-and-trial iterations before the fabrication of final metamaterial prototypes, thus delaying the overall processing time. In recent years, a few significant new artificial intelligence-based techniques like topological optimization and machine learning have shown great potential in various research fields, including genetics, astrophysics, manufacturing, and nanomaterials, and engineering.

Topological optimization is a mathematics-based optimization technique prominently used in the selection of structural design for achieving the objectives. The topology optimization has been 
proven to be a constructive tool for the identification of optimal settings in the early stage of the design process. It finds a wide range of applications in mechanical, aerospace, biochemical, and civil engineering fields. Several optimality criteria methods such as genetic algorithms, simulated annealing algorithms, and particle swarm are being used in for topological optimization. Among them, the genetic algorithm has been efficiently used in structural design optimizations $[113,114]$. The genetic algorithm is an artificial intelligence-based search and optimization technique, inspired by evolutionary biology processes such as selection, crossover, and mutation, to obtain global and robust optimal solutions for optimization problems $[115,116]$. More detailed information on topology optimization can be found in many published articles [117,118].

Machine learning is another artificial intelligence (AI)-based technique that provides systems with the ability of automatic learning by performing data analysis, development of predictive models, being self-"trained" to produce outputs, make decisions, and improve from the past experiences. Using machine learning, approximate desired results can be obtained from a large number of datasets. The field of machine learning is very diverse and many forms of machine learning algorithms are available. However, in recent times, the artificial neural networks technique has been extensively employed in machine learning for many applications [119]. The artificial neural network is also known as a curve-fitting approximation method or deep-learning method that uses multiple layers of matrix multiplications with nonlinear objective functions applied between each matrix operation. Several published articles can be reviewed for detailed information on machine learning techniques.

These data-analytics-based technologies have been used to improve accuracy, reduce trial-and-error steps, shorten unplanned downtimes, improve transition times, and increase productivity. However, in the acoustic metamaterial research domain, the utilization of these techniques is at the initial stage. Numerous works have been reported in the acoustic metamaterial field [120-128]. Recently, Bianco et al. [129] discussed the recent advances and transformative potential of machine learning (ML), including deep learning, in the field of acoustics. The field of acoustic metamaterials is in a fledgling stage, and by incorporating these emerging tools, the current approaches towards the designing and development of acoustic metamaterials may be progressed into an advanced stage. Artificial intelligence-based machine learning can further lead to the development of intricate designs with more sophisticated metamaterial prototypes.

II. Implementation of auxetic metamaterials for acoustic applications. Auxetic metamaterials are the purposefully designed architectures that possess unusual mechanical properties, like a negative Poisson ratio [130-134]. Contrary to the conventional materials, the auxetic metamaterials demonstrate lateral shrinkage while being compressed, thus endowing several desirable properties, such as variable permeability, high energy absorption ability, enhanced mechanical resistance, and synclastic behavior [135]. Due to these remarkable properties, auxetic mechanical metamaterials can play a significant role in the fabrication of lightweight and mechanically stable metastructures for sound attenuation. In high-rise buildings, the installation of these auxetic structure-based lightweight ventilated acoustic window panels is desirable.

II. In-situ sound wave manipulation. In recent times, active acoustic metamaterials have gained significant interest among acoustic researchers [136]. The sound attenuation performances of the active or tunable acoustic metamaterials can be adjusted by tuning inherent characteristics, such as membrane tension, in membrane-type metamaterials. Due to the boundless variants of active controls, the research in this direction could be up-and-coming. Moreover, resonant behavior and the effective acoustic parameters (mass density and bulk modulus) of the acoustic metamaterials have been tuned by the thermal energy [137]. Using this technique, the band gap can be tuned for the desired frequency range.

III. Detailed investigations into ventilation performance. It is challenging to conduct ventilation tests for laboratory-scale prototypes as suitable fan systems will need to be designed and installed for delivering the designed airflow patterns. Potentially, it is possible to install the prototypes in a wind tunnel for the evaluation of ventilation patterns or on a desktop wind tunnel for small-scale prototypes. 
IV. Scaling-up. The laboratory-based acoustic metastructure prototypes have shown promising results. However, the acoustical performances of these prototypes at scaled-up dimensions may differ from the laboratory-based results. There is an inherent need for the fabrication of larger specimens for performance testing as well as commercial applications. Furthermore, additive manufacturing (AM), also known as 3D printing, is the most commonly used current technology for the fabrication of metastructures. There is a variety of 3D printing techniques that are available, and appropriate selection of the 3D printing process plays a crucial role [138]. Moreover, 3D printing is not yet a sustainable mass production technology and hence is expensive. The recent developments in advanced manufacturing technologies such as $4 \mathrm{D}$ printing have enabled the fabrication of acoustic metamaterials with complex architectures across several length scales, with feature sizes of several meters for a wide range of materials.

\section{Conclusions}

In this review, a historical perspective of acoustic metamaterials has been initially discussed in the introduction. Subsequently, the concept of numerous acoustic metamaterial categories has been discussed. Several notable designs of acoustic metamaterials for both sound attenuation and air ventilation applications have been discussed in greater detail. The presented prototypes have shown acoustic performance in wide frequency ranges, from low-to-mid frequencies to mid-to-high frequencies. However, Helmholtz resonance-based metastructures are proven to be useful for tonal noise mitigations. The newly developed design concepts like space coiling have revealed wideband noise attenuation and enable efficient ventilation if designed accordingly.

Finally, a perspective on the possible future developments in the field regarding metamaterial design and modeling, fabrication, testing, and characterization methods has been discussed. The outlook may provide a possible emerging direction for researchers which could be further investigated and hopefully lead to the industrial application of acoustic metamaterials across multiple disciplines.

Author Contributions: S.K. and H.P.L. drafted the outline and wrote the manuscript. All authors have read and agreed to the published version of the manuscript.

Funding: This research received no external funding.

Acknowledgments: The first author would like to acknowledge the financial support from the Ministry of education RSB Research Fellowship.

Conflicts of Interest: The authors declare no conflict of interest.

\section{References}

1. Veselago, V.G. The electrodynamics of substances with simultaneously negative values of and $\mu$. Sov. Phys. Uspekhi 1968, 10, 509. [CrossRef]

2. Walser,R.M. Metamaterials: An introduction. In Introduction to Complex Mediums for Optics and Electromagnetics; 2003; Volume 1, pp. 295-316. [CrossRef]

3. Pendry, J.B.; Holden, A.; Stewart, W.; Youngs, I. Extremely low frequency plasmons in metallic mesostructures. Phys. Rev. Lett. 1996, 76, 4773. [CrossRef] [PubMed]

4. Pendry, J.B.; Holden, A.J.; Robbins, D.J.; Stewart, W. Magnetism from conductors and enhanced nonlinear phenomena. IEEE Trans. Microw. Theory Tech. 1999, 47, 2075-2084. [CrossRef]

5. Shelby, R.A.; Smith, D.R.; Schultz, S. Experimental verification of a negative index of refraction. Science 2001, 292, 77-79. [CrossRef] [PubMed]

6. Engheta, N. An idea for thin subwavelength cavity resonators using metamaterials with negative permittivity and permeability. IEEE Antennas Wirel. Propag. Lett. 2002, 1, 10-13. [CrossRef]

7. Ziolkowski, R.W. Design, fabrication, and testing of double negative metamaterials. IEEE Trans. Antennas Propag. 2003, 51, 1516-1529. [CrossRef]

8. Pendry, J.B. Negative refraction makes a perfect lens. Phys. Rev. Lett. 2000, 85, 3966. [CrossRef] 
9. Soukoulis, C.M.; Linden, S.; Wegener, M. Negative refractive index at optical wavelengths. Science 2007, 315, 47-49. [CrossRef]

10. Soukoulis, C.M.; Wegener, M. Past achievements and future challenges in the development of three-dimensional photonic metamaterials. Nat. Photonics 2011, 5, 523. [CrossRef]

11. Liu, Z.; Zhang, X.; Mao, Y.; Zhu, Y.; Yang, Z.; Chan, C.; Sheng, P. Locally resonant sonic materials. Science 2000, 289, 1734-1736. [CrossRef]

12. Weber, L.; Gomez-Agustina, L. Investigation into the application of an acoustic metamaterial for sound attenuation with air-flow. ICSV22 Proc. Florence Italy Pap. 2015, 0508105747633.

13. Ma, G.; Sheng, P. Acoustic metamaterials: From local resonances to broad horizons. Sci. Adv. 2016, 2, e1501595. [CrossRef] [PubMed]

14. Ge, H.; Yang, M.; Ma, C.; Lu, M.-H.; Chen, Y.-F.; Fang, N.; Sheng, P. Breaking the barriers: Advances in acoustic functional materials. Natl. Sci. Rev. 2017, 5, 159-182. [CrossRef]

15. Kumar, S.; Lee, H.P. The present and future role of acoustic metamaterials for architectural and urban noise mitigations. Acoustics 2019, 1, 590-607. [CrossRef]

16. Yablonovitch, E. Inhibited spontaneous emission in solid-state physics and electronics. Phys. Rev. Lett. 1987, 58, 2059. [CrossRef] [PubMed]

17. John, S. Strong localization of photons in certain disordered dielectric superlattices. Phys. Rev. Lett. 1987, 58, 2486. [CrossRef] [PubMed]

18. Yablonovitch, E.; Gmitter, T.; Leung, K.-M. Photonic band structure: The face-centered-cubic case employing nonspherical atoms. Phys. Rev. Lett. 1991, 67, 2295. [CrossRef]

19. Cubukcu, E.; Aydin, K.; Ozbay, E.; Foteinopoulou, S.; Soukoulis, C.M. Negative refraction by photonic crystals. Nature 2003, 423, 604-605. [CrossRef]

20. Reed, E.J.; Soljačić, M.; Joannopoulos, J.D. Reversed doppler effect in photonic crystals. Phys. Rev. Lett. 2003, 91, 133901. [CrossRef]

21. Shi, X.; Lin, X.; Kaminer, I.; Gao, F.; Yang, Z.; Joannopoulos, J.D.; Soljačić, M.; Zhang, B. Superlight inverse Doppler effect. Nat. Phys. 2018, 14, 1001-1005. [CrossRef]

22. Xi, S.; Chen, H.; Jiang, T.; Ran, L.; Huangfu, J.; Wu, B.-I.; Kong, J.A.; Chen, M. Experimental verification of reversed Cherenkov radiation in left-handed metamaterial. Phys. Rev. Lett. 2009, 103, 194801. [CrossRef] [PubMed]

23. Lin, X.; Easo, S.; Shen, Y.; Chen, H.; Zhang, B.; Joannopoulos, J.D.; Soljačić, M.; Kaminer, I. Controlling cherenkov angles with resonance transition radiation. Nat. Phys. 2018, 14, 816-821. [CrossRef]

24. Luo, C.; Johnson, S.G.; Joannopoulos, J.; Pendry, J. Subwavelength imaging in photonic crystals. Phys. Rev. B 2003, 68, 045115. [CrossRef]

25. Kushwaha, M.S.; Halevi, P.; Dobrzynski, L.; Djafari-Rouhani, B. Acoustic band structure of periodic elastic composites. Phys. Rev. Lett. 1993, 71, 2022. [CrossRef]

26. Psarobas, I.E. Phononic crystals-sonic band-gap materials. Z. Krist.-Cryst. Mater. 2005, 220, IV. [CrossRef]

27. Lu, M.-H.; Feng, L.; Chen, Y.-F. Phononic crystals and acoustic metamaterials. Mater. Today 2009, 12, 34-42. [CrossRef]

28. Bloch, F. Elektron im periodischen Potential, Bändermodell des Festkörpers, Z. Phys 1928, 52, 555. [CrossRef]

29. Kittel, C.; McEuen, P. Introduction to Solid State Physics; Wiley: New York, NY, USA, 1976; Volume 8.

30. Ruzzene, M.; Scarpa, F. Directional and band-gap behavior of periodic auxetic lattices. Phys. Status Solidi (b) 2005, 242, 665-680. [CrossRef]

31. Gorishnyy, T.; Maldovan, M.; Ullal, C.; Thomas, E. Sound ideas. Phys. World 2005, 18, 24. [CrossRef]

32. Deymier, P.A. Acoustic Metamaterials and Phononic Crystals; Springer Science \& Business Media: Berlin, Germany, 2013; Volume 173.

33. Khelif, A.; Adibi, A. Phononic Crystals; Springer: New York, NY, USA, 2015. [CrossRef]

34. Sigalas, M.; Economou, E.N. Band structure of elastic waves in two dimensional systems. Solid State Commun. 1993, 86, 141-143. [CrossRef]

35. De Espinosa, F.M.; Jimenez, E.; Torres, M. Ultrasonic band gap in a periodic two-dimensional composite. Phys. Rev. Lett. 1998, 80, 1208. [CrossRef]

36. Sánchez-Pérez, J.V.; Caballero, D.; Mártinez-Sala, R.; Rubio, C.; Sánchez-Dehesa, J.; Meseguer, F.; Llinares, J.; Gálvez, F. Sound attenuation by a two-dimensional array of rigid cylinders. Phys. Rev. Lett. 1998, 80, 5325. [CrossRef] 
37. Fok, L.; Ambati, M.; Zhang, X. Acoustic metamaterials. MRS Bull. 2008, 33, 931-934. [CrossRef]

38. Fokin, V.; Ambati, M.; Sun, C.; Zhang, X. Method for retrieving effective properties of locally resonant acoustic metamaterials. Phys. Rev. B 2007, 76, 144302. [CrossRef]

39. Huang, H.; Sun, C. Wave attenuation mechanism in an acoustic metamaterial with negative effective mass density. New J. Phys. 2009, 11, 013003. [CrossRef]

40. Lee, S.H.; Wright, O.B. Origin of negative density and modulus in acoustic metamaterials. Phys. Rev. B 2016, 93, 024302. [CrossRef]

41. Yang, Z.; Mei, J.; Yang, M.; Chan, N.; Sheng, P. Membrane-type acoustic metamaterial with negative dynamic mass. Phys. Rev. Lett. 2008, 101, 204301. [CrossRef]

42. Lee, S.H.; Park, C.M.; Seo, Y.M.; Wang, Z.G.; Kim, C.K. Acoustic metamaterial with negative density. Phys. Lett. A 2009, 373, 4464-4469. [CrossRef]

43. Chen, J.-S.; Chien, I.-T. Dynamic behavior of a metamaterial beam with embedded membrane-mass structures. J. Appl. Mech. 2017, 84, 121007. [CrossRef]

44. Yang, M.; Li, Y.; Meng, C.; Fu, C.; Mei, J.; Yang, Z.; Sheng, P. Sound absorption by subwavelength membrane structures: A geometric perspective. Comptes Rendus Mécanique 2015, 343, 635-644. [CrossRef]

45. Fang, N.; Xi, D.; Xu, J.; Ambati, M.; Srituravanich, W.; Sun, C.; Zhang, X. Ultrasonic metamaterials with negative modulus. Nat. Mater. 2006, 5, 452-456. [CrossRef] [PubMed]

46. Li, J.; Chan, C. Double-negative acoustic metamaterial. Phys. Rev. E 2004, 70, 055602. [CrossRef] [PubMed]

47. Ding, Y.; Liu, Z.; Qiu, C.; Shi, J. Metamaterial with simultaneously negative bulk modulus and mass density. Phys. Rev. Lett. 2007, 99, 093904. [CrossRef] [PubMed]

48. Burov, V.; Dmitriev, K.; Sergeev, S. Acoustic double-negative media. Acoust. Phys. 2009, 55, $298-310$. [CrossRef]

49. Fok, L.; Zhang, X. Negative acoustic index metamaterial. Phys. Rev. B 2011, 83, 214304. [CrossRef]

50. Lee, S.H.; Park, C.M.; Seo, Y.M.; Wang, Z.G.; Kim, C.K. Composite acoustic medium with simultaneously negative density and modulus. Phys. Rev. Lett. 2010, 104, 054301. [CrossRef]

51. Yang, M.; Ma, G.; Yang, Z.; Sheng, P. Coupled membranes with doubly negative mass density and bulk modulus. Phys. Rev. Lett. 2013, 110, 134301. [CrossRef]

52. Wu, Y.; Lai, Y.; Zhang, Z.-Q. Elastic metamaterials with simultaneously negative effective shear modulus and mass density. Phys. Rev. Lett. 2011, 107, 105506. [CrossRef]

53. Chen, H.; Zeng, H.; Ding, C.; Luo, C.; Zhao, X. Double-negative acoustic metamaterial based on hollow steel tube meta-atom. J. Appl. Phys. 2013, 113, 104902. [CrossRef]

54. Brunet, T.; Merlin, A.; Mascaro, B.; Zimny, K.; Leng, J.; Poncelet, O.; Aristégui, C.; Mondain-Monval, O. Soft 3D acoustic metamaterial with negative index. Nat. Mater. 2015, 14, 384. [CrossRef]

55. Cheng, Y.; Zhou, C.; Yuan, B.; Wu, D.; Wei, Q.; Liu, X. Ultra-sparse metasurface for high reflection of low-frequency sound based on artificial mie resonances. Nat. Mater. 2015, 14, 1013-1019. [CrossRef] [PubMed]

56. Alu, A.; Silveirinha, M.G.; Salandrino, A.; Engheta, N. Epsilon-near-zero metamaterials and electromagnetic sources: Tailoring the radiation phase pattern. Phys. Rev. B 2007, 75, 155410. [CrossRef]

57. Fleury, R.; Alù, A. Extraordinary sound transmission through density-near-zero ultranarrow channels. Phys. Rev. Lett. 2013, 111, 055501. [CrossRef] [PubMed]

58. Wu, Y.; Li, J. Total reflection and cloaking by zero index metamaterials loaded with rectangular dielectric defects. Appl. Phys. Lett. 2013, 102, 183105. [CrossRef]

59. Li, Y.; Liang, B.; Tao, X.; Zhu, X.-F.; Zou, X.-Y.; Cheng, J.-C. Acoustic focusing by coiling up space. Appl. Phys. Lett. 2012, 101, 233508. [CrossRef]

60. Cai, X.; Guo, Q.; Hu, G.; Yang, J. Ultrathin low-frequency sound absorbing panels based on coplanar spiral tubes or coplanar helmholtz resonators. Appl. Phys. Lett. 2014, 105, 121901. [CrossRef]

61. Yang, Z.; Gao, F.; Shi, X.; Lin, X.; Gao, Z.; Chong, Y.; Zhang, B. Topological acoustics. Phys. Rev. Lett. 2015, 114, 114301. [CrossRef]

62. Song, G.Y.; Cheng, Q.; Huang, B.; Dong, H.Y.; Cui, T.J. Broadband fractal acoustic metamaterials for low-frequency sound attenuation. Appl. Phys. Lett. 2016, 109, 131901. [CrossRef]

63. Liu, J.; Li, L.; Xia, B.; Man, X. Fractal labyrinthine acoustic metamaterial in planar lattices. Int. J. Solids Struct. 2018, 132, 20-30. [CrossRef] 
64. Man, X.; Luo, Z.; Liu, J.; Xia, B. Hilbert fractal acoustic metamaterials with negative mass density and bulk modulus on subwavelength scale. Mater. Des. 2019, 180, 107911. [CrossRef]

65. Man, X.-F.; Xia, B.-Z.; Luo, Z.; Liu, J. 3D Hilbert fractal acoustic metamaterials: Low-frequency and multi-band sound insulation. J. Phys. D Appl. Phys. 2019, 52, 195302. [CrossRef]

66. Zhao, X.; Liu, G.; Xia, D. Maze-like acoustic metamaterial for low-frequency broadband noise suppression. Appl. Phys. Express 2020, 13, 027002.

67. Zhu, X.; Li, K.; Zhang, P.; Zhu, J.; Zhang, J.; Tian, C.; Liu, S. Implementation of dispersion-free slow acoustic wave propagation and phase engineering with helical-structured metamaterials. Nat. Commun. 2016, 7, 11731. [CrossRef] [PubMed]

68. Esfahlani, H.; Lissek, H.; Mosig, J.R. Generation of acoustic helical wavefronts using metasurfaces. Phys. Rev. B 2017, 95, 024312. [CrossRef]

69. Li, Y.; Jiang, X.; Li, R.-Q.; Liang, B.; Zou, X.-Y.; Yin, L.-L.; Cheng, J.-C. Experimental realization of full control of reflected waves with subwavelength acoustic metasurfaces. Phys. Rev. Appl. 2014, 2, 064002. [CrossRef]

70. Zhong, J.; Zhao, H.; Yang, H.; Wang, Y.; Yin, J.; Wen, J. Theoretical requirements and inverse design for broadband perfect absorption of low-frequency waterborne sound by ultrathin metasurface. Sci. Rep. 2019, 9, 1181. [CrossRef] [PubMed]

71. Liang, Z.; Li, J. Extreme acoustic metamaterial by coiling up space. Phys. Rev. Lett. 2012, $108,114301$. [CrossRef]

72. Liu, C.; Luo, J.; Lai, Y. Acoustic metamaterials with broadband and wide-angle impedance matching. Phys. Rev. Mater. 2018, 2, 045201. [CrossRef]

73. Chen, C.; Du, Z.; Hu, G.; Yang, J. A low-frequency sound absorbing material with subwavelength thickness. Appl. Phys. Lett. 2017, 110, 221903. [CrossRef]

74. Li, Y.; Assouar, B.M. Acoustic metasurface-based perfect absorber with deep subwavelength thickness. Appl. Phys. Lett. 2016, 108, 063502. [CrossRef]

75. Huang, S.; Fang, X.; Wang, X.; Assouar, B.; Cheng, Q.; Li, Y. Acoustic perfect absorbers via spiral metasurfaces with embedded apertures. Appl. Phys. Lett. 2018, 113, 233501. [CrossRef]

76. Zhang, C.; Hu, X. Three-dimensional single-port labyrinthine acoustic metamaterial: Perfect absorption with large bandwidth and tunability. Phys. Rev. Appl. 2016, 6, 064025. [CrossRef]

77. Long, H.; Shao, C.; Liu, C.; Cheng, Y.; Liu, X. Broadband near-perfect absorption of low-frequency sound by subwavelength metasurface. Appl. Phys. Lett. 2019, 115, 103503. [CrossRef]

78. Shen, Y.; Yang, Y.; Guo, X.; Shen, Y.; Zhang, D. Low-frequency anechoic metasurface based on coiled channel of gradient cross-section. Appl. Phys. Lett. 2019, 114, 083501. [CrossRef]

79. Kumar, S.; Bhushan, P.; Prakash, O.; Bhattacharya, S. Double negative acoustic metastructure for attenuation of acoustic emissions. Appl. Phys. Lett. 2018, 112, 101905. [CrossRef]

80. Ghaffarivardavagh, R.; Nikolajczyk, J.; Holt, R.G.; Anderson, S.; Zhang, X. Horn-like space-coiling metamaterials toward simultaneous phase and amplitude modulation. Nat. Commun. 2018, 9, 1349. [CrossRef]

81. Xie, Y.; Popa, B.-I.; Zigoneanu, L.; Cummer, S.A. Measurement of a broadband negative index with space-coiling acoustic metamaterials. Phys. Rev. Lett. 2013, 110, 175501. [CrossRef]

82. Corbusier, L. Towards a New Architecture; Courier Corporation: New York, NY, USA, 2013.

83. Bajraktari, E.; Lechleitner, J.; Mahdavi, A. The sound insulation of double facades with openings for natural ventilation. Build. Acoust. 2015, 22, 163-176. [CrossRef]

84. Zuccherini Martello, N.; Fausti, P.; Santoni, A.; Secchi, S. The use of sound absorbing shading systems for the attenuation of noise on building facades. An experimental investigation. Buildings 2015, 5, 1346-1360. [CrossRef]

85. Tong, Y.; Tang, S. Plenum window insertion loss in the presence of a line source-A scale model study. J. Acoust. Soc. Am. 2013, 133, 1458-1467. [CrossRef]

86. Tong, Y.; Tang, S.; Kang, J.; Fung, A.; Yeung, M. Full scale field study of sound transmission across plenum windows. Appl. Acoust. 2015, 89, 244-253. [CrossRef]

87. Tang, S. Reduction of sound transmission across plenum windows by incorporating an array of rigid cylinders. J. Sound Vib. 2018, 415, 25-40. [CrossRef]

88. Li, X.; Tong, Y.; Tang, S.; Lau, K. Empirical prediction of traffic noise transmission loss across plenum windows. Appl. Acoust. 2019, 151, 45-54. [CrossRef] 
89. Lee, H.M.; Wang, Z.; Lim, K.M.; Xie, J.; Lee, H.P. Novel plenum window with sonic crystals for indoor noise control. Appl. Acoust. 2020, 167, 107390.

90. Kim, S.-H.; Lee, S.-H. Air transparent soundproof window. AIP Adv. 2014, 4, 117123. [CrossRef]

91. Wang, Z.; Hui, C.; $\mathrm{Ng}, \mathrm{C}$. The acoustic performance of ventilated window with quarter-wave resonators and membrane absorber. Appl. Acoust. 2014, 78, 1-6. [CrossRef]

92. Yu, X.; Lu, Z.; Cheng, L.; Cui, F. On the sound insulation of acoustic metasurface using a sub-structuring approach. J. Sound Vib. 2017, 401, 190-203. [CrossRef]

93. Jung, J.W.; Kim, J.E.; Lee, J.W. Acoustic metamaterial panel for both fluid passage and broadband soundproofing in the audible frequency range. Appl. Phys. Lett. 2018, 112, 041903. [CrossRef]

94. Kumar, S.; Xiang, T.B.; Lee, H.P. Ventilated acoustic metamaterial window panels for simultaneous noise shielding and air circulation. Appl. Acoust. 2020, 159, 107088. [CrossRef]

95. Wang, X.; Luo, X.; Yang, B.; Huang, Z. Ultrathin and durable open metamaterials for simultaneous ventilation and sound reduction. Appl. Phys. Lett. 2019, 115, 171902. [CrossRef]

96. Yang, J.; Lee, J.S.; Lee, H.R.; Kang, Y.J.; Kim, Y.Y. Slow-wave metamaterial open panels for efficient reduction of low-frequency sound transmission. Appl. Phys. Lett. 2018, 112, 091901. [CrossRef]

97. Zhang, H.-L.; Zhu, Y.-F.; Liang, B.; Yang, J.; Yang, J.; Cheng, J.-C. Omnidirectional ventilated acoustic barrier. Appl. Phys. Lett. 2017, 111, 203502. [CrossRef]

98. Yu, X.; Lu, Z.; Liu, T.; Cheng, L.; Zhu, J.; Cui, F. Sound transmission through a periodic acoustic metamaterial grating. J. Sound Vib. 2019, 449, 140-156. [CrossRef]

99. Ghaffarivardavagh, R.; Nikolajczyk, J.; Anderson, S.; Zhang, X. Ultra-open acoustic metamaterial silencer based on Fano-like interference. Phys. Rev. B 2019, 99, 024302. [CrossRef]

100. Sun, M.; Fang, X.; Mao, D.; Wang, X.; Li, Y. Broadband Acoustic Ventilation Barriers. Phys. Rev. Appl. 2020, 13, 044028. [CrossRef]

101. Shen, C.; Xie, Y.; Li, J.; Cummer, S.A.; Jing, Y. Acoustic metacages for sound shielding with steady air flow. J. Appl. Phys. 2018, 123, 124501. [CrossRef]

102. Melnikov, A.; Maeder, M.; Friedrich, N.; Pozhanka, Y.; Wollmann, A.; Scheffler, M.; Oberst, S.; Powell, D.; Marburg, S. Acoustic metamaterial capsule for reduction of stage machinery noise. J. Acoust. Soc. Am. 2020, 147, 1491-1503. [CrossRef]

103. Yang, M.; Sheng, P. Sound absorption structures: From porous media to acoustic metamaterials. Annu. Rev. Mater. Res. 2017, 47, 83-114. [CrossRef]

104. Lee, T.; Nomura, T.; Dede, E.M.; Iizuka, H. Ultrasparse acoustic absorbers enabling fluid flow and visible-light controls. Phys. Rev. Appl. 2019, 11, 024022. [CrossRef]

105. Lee, T.; Nomura, T.; Iizuka, H. Damped resonance for broadband acoustic absorption in one-port and two-port systems. Sci. Rep. 2019, 9, 1-11. [CrossRef]

106. Li, L.-J.; Zheng, B.; Zhong, L.-M.; Yang, J.; Liang, B.; Cheng, J.-C. Broadband compact acoustic absorber with high-efficiency ventilation performance. Appl. Phys. Lett. 2018, 113, 103501. [CrossRef]

107. Wu, X.; Au-Yeung, K.Y.; Li, X.; Roberts, R.C.; Tian, J.; Hu, C.; Huang, Y.; Wang, S.; Yang, Z.; Wen, W. High-efficiency ventilated metamaterial absorber at low frequency. Appl. Phys. Lett. 2018, 112, 103505. [CrossRef]

108. Kumar, S.; Lee, H.P. Labyrinthine acoustic metastructures enabling broadband sound absorption and ventilation. Appl. Phys. Lett. 2020, 116, 134103. [CrossRef]

109. Xiang, X.; Wu, X.; Li, X.; Wu, P.; He, H.; Mu, Q.; Wang, S.; Huang, Y.; Wen, W. Ultra-open ventilated metamaterial absorbers for sound-silencing applications in environment with free air flows. Extrem. Mech. Lett. 2020, 100786. [CrossRef]

110. Ge, Y.; Sun, H.-X.; Yuan, S.-Q.; Lai, Y. Broadband unidirectional and omnidirectional bidirectional acoustic insulation through an open window structure with a metasurface of ultrathin hooklike meta-atoms. Appl. Phys. Lett. 2018, 112, 243502. [CrossRef]

111. Ge, Y.; Sun, H.-X.; Yuan, S.-Q.; Lai, Y. Switchable omnidirectional acoustic insulation through open window structures with ultrathin metasurfaces. Phys. Rev. Mater. 2019, 3, 065203. [CrossRef]

112. Zadpoor, A.A. Mechanical meta-materials. Mater. Horiz. 2016, 3, 371-381. [CrossRef]

113. Chapman, C.D.; Saitou, K.; Jakiela, M.J. Genetic algorithms as an approach to configuration and topology design. J. Mech. Des. 1994, 116, 1005-1012. [CrossRef]

114. Jakiela, M.J.; Chapman, C.; Duda, J.; Adewuya, A.; Saitou, K. Continuum structural topology design with genetic algorithms. Comput. Methods Appl. Mech. Eng. 2000, 186, 339-356. [CrossRef] 
115. Goldenberg, D.E. Genetic Algorithms in Search, Optimization and Machine Learning; Addison Wesley: Reading, MA, USA, 1989.

116. Kumar, S.; Dubey, A.K.; Pandey, A.K. Computer-aided genetic algorithm based multi-objective optimization of laser trepan drilling. Int. J. Precis. Eng. Manuf. 2013, 14, 1119-1125. [CrossRef]

117. Bendsoe, M.P.; Sigmund, O. Topology Optimization: Theory, Methods, and Applications; Springer Science \& Business Media: Berlin, Germany, 2013.

118. Huber, S.D. Topological mechanics. Nat. Phys. 2016, 12, 621-623. [CrossRef]

119. Hawley, S.H.; Chatziiannou, V.; Morrison, A. Synthesis of musical instrument sounds: Physics-based modeling or machine learning? Phys. Today 2020, 16, 20-28. [CrossRef]

120. Li, D.; Zigoneanu, L.; Popa, B.-I.; Cummer, S.A. Design of an acoustic metamaterial lens using genetic algorithms. J. Acoust. Soc. Am. 2012, 132, 2823-2833. [CrossRef] [PubMed]

121. Lu, L.; Yamamoto, T.; Otomori, M.; Yamada, T.; Izui, K.; Nishiwaki, S. Topology optimization of an acoustic metamaterial with negative bulk modulus using local resonance. Finite Elem. Anal. Des. 2013, 72, 1-12. [CrossRef]

122. Souslov, A.; Van Zuiden, B.C.; Bartolo, D.; Vitelli, V. Topological sound in active-liquid metamaterials. Nat. Phys. 2017, 13, 1091-1094. [CrossRef]

123. Han, X.; Zhang, Z. Topological optimization of phononic crystal thin plate by a genetic algorithm. Sci. Rep. 2019, 9, 1-13. [CrossRef]

124. Bacigalupo, A.; Gnecco, G.; Lepidi, M.; Gambarotta, L. Machine-learning techniques for the optimal design of acoustic metamaterials. J. Optim. Theory Appl. 2019, 1-24. [CrossRef]

125. Han, X.; Zhang, Z. Bandgap design of three-phase phononic crystal by topological optimization. Wave Motion 2020, 93, 102496. [CrossRef]

126. Jung, J.; Goo, S.; Kook, J. Design of a local resonator using topology optimization to tailor bandgaps in plate structures. Mater. Des. 2020, 108627. [CrossRef]

127. Dong, H.-W.; Zhao, S.-D.; Wang, Y.-S.; Cheng, L.; Zhang, C. Robust 2D/3D multi-polar acoustic metamaterials with broadband double negativity. J. Mech. Phys. Solids 2020, 137, 103889. [CrossRef]

128. Weiner, M.; Ni, X.; Li, M.; Alù, A.; Khanikaev, A.B. Demonstration of a third-order hierarchy of topological states in a three-dimensional acoustic metamaterial. Sci. Adv. 2020, 6, eaay4166. [CrossRef] [PubMed]

129. Bianco, M.J.; Gerstoft, P.; Traer, J.; Ozanich, E.; Roch, M.A.; Gannot, S.; Deledalle, C.-A. Machine learning in acoustics: Theory and applications. J. Acoust. Soc. Am. 2019, 146, 3590-3628. [CrossRef] [PubMed]

130. Wojciechowski, K. Constant thermodynamic tension monte carlo studies of elastic properties of a two-dimensional system of hard cyclic hexamers. Mol. Phys. 1987, 61, 1247-1258. [CrossRef]

131. Wojciechowski, K. Two-dimensional isotropic system with a negative poisson ratio. Phys. Lett. A 1989, 137, 60-64. [CrossRef]

132. Alderson, A.; Rasburn, J.; Ameer-Beg, S.; Mullarkey, P.G.; Perrie, W.; Evans, K.E. An auxetic filter: A tuneable filter displaying enhanced size selectivity or defouling properties. Ind. Eng. Chem. Res. 2000, 39, 654-665. [CrossRef]

133. Kolken, H.M.; Zadpoor, A. Auxetic mechanical metamaterials. RSC Adv. 2017, 7, 5111-5129. [CrossRef]

134. Jiang, Y.; Liu, Z.; Matsuhisa, N.; Qi, D.; Leow, W.R.; Yang, H.; Yu, J.; Chen, G.; Liu, Y.; Wan, C. Auxetic mechanical metamaterials to enhance sensitivity of stretchable strain sensors. Adv. Mater. 2018, 30, 1706589. [CrossRef]

135. Li, J.; Slesarenko, V.; Rudykh, S. Auxetic multiphase soft composite material design through instabilities with application for acoustic metamaterials. Soft Matter 2018, 14, 6171-6180. [CrossRef]

136. Kumar, S.; Lee, H.P. Recent Advances in Active Acoustic Metamaterials. Int. J. Appl. Mech. 2019, 11, 1950081. [CrossRef]

137. Li, Z.; Li, Y.; Kumar, S.; Lee, H.P. Thermal tuning of negative effective mass density in a two-dimensional acoustic metamaterial with hexagonal lattice. J. Appl. Phys. 2019, 126, 155102. [CrossRef]

138. Kumar, S.; Bhushan, P.; Pandey, M.; Bhattacharya, S. Additive manufacturing as an emerging technology for fabrication of microelectromechanical systems (MEMS). J. Micromanuf. 2019, 2, 175-197. [CrossRef]

(C) 2020 by the authors. Licensee MDPI, Basel, Switzerland. This article is an open access article distributed under the terms and conditions of the Creative Commons Attribution (CC BY) license (http://creativecommons.org/licenses/by/4.0/). 